\title{
Title Change
}

Characteristics of

Academic and

Nonacademic Serials

\section{Implications for Identifying New Serial Works}

\author{
Mavis B. Molto
}

The study compared the characteristics of academic and nonacademic serials with title changes, from which it was determined that the two serial subpopulations were similar in the six broad reasons found for a title change but differed in the kinds and proportions of subject and function changes that occurred when a title changed. On the basis of the findings, two alternate RDA rule revision proposals are made (labeled Ideal versus Practical), the first requiring a new access point for a title change only when a significant subject or function change has occurred, and the second requiring a new access point only when the publisher has indicated the start of a totally new serial. It is further recommended that reasons for title changes be determined from statements in the serial or directly from the editor or publisher rather than from word changes in the title.

Mavis B. Molto (mavismolto@gmail.com) is a Serials Cataloger at Utah State University, Logan, Utah.

Manuscript submitted April 18, 2016; returned to author for revision August 9. 2016; revised manuscript submitted August 23, 2016; accepted for publication September 9, 2016.
A $\mathrm{n}$ important element in RDA (Resource Description and Access) is the A concept of a work. However, for serials with title changes, the rules do not provide a logical mechanism for identifying a new work. The $R D A$ rules for serials with title changes, mostly a carryover from AACR2 (Anglo-American Cataloging Rules, second edition), consist of determining whether a major change has occurred in the title. A major change occurs when certain types of title words change or when a change occurs in the first five words of the title. If a major change occurs, a new access point or record is created, which signals also that a new work has emerged. ${ }^{1}$ This is inconsistent with what one would logically see as a new work as defined in RDA: "a distinct intellectual or artistic creation."

In two previous studies, the author proposed changes to the $R D A$ rules because of findings from a sample of academic serials with title changes. It is unclear, however, to what extent these findings can be applied to nonacademic serials because there is no correlating data for them. Because of these questions, it was determined that it was necessary to conduct a new study focusing on nonacademic serials so that comparisons could be made with the previous findings. The new data could then be used to expand on the previous recommendations for $R D A$ rule changes. 
The current study differs from other studies of title changes in two ways. First, the study compares two serial subpopulations, namely academic serials with title changes and nonacademic serials with title changes. Previous studies identifying reasons for title changes have either focused on academic and scientific serials or have looked at a mix of serial subpopulations. Second, the study, along with the author's previous studies of academic serials, has the objective of using the collected data to recommend better cataloging procedures for identifying new serial works.

The purpose of the study was thus to compare the characteristics of academic and nonacademic serials with title changes and to develop a collective strategy for identifying new works for these serials. The study was limited to serials with title changes and did not address other kinds of serial changes (e.g., changes in responsibility) that might also lead to the recognition of a new work. The study was further limited to English-language serials to correlate with the author's earlier studies. The research is expected to have both theoretical and practical implications, with the findings contributing to the theoretical body of knowledge concerning title changes for serials and also providing information for improving the $R D A$ rules for serials with title changes.

\section{Literature Review}

The literature review concerns six areas related to the proposed research: (1) characteristics of serials with title changes, (2) comparisons of academic and nonacademic serials, (3) the concept of a work, (4) strategies for identifying new works for serials with title changes, (5) international cataloging standards, and (6) the future of serials cataloging. The six topics are discussed below.

\section{Characteristics of Serials with Title Changes}

Characteristics of serials with title changes was the topic of a previous study by the author in which reasons for title changes were identified in academic serials. ${ }^{3}$ Several older studies, by Afes and Wrynn, Geller, and Lakhanpal, along with a five-part study by Guha, Sen, and Neogi, investigated reasons for title changes in scholarly and scientific serials. ${ }^{4} \mathrm{~A}$ study by Jones reported reasons for title changes from a sample of serials drawn from the Standard Periodical Directory covering a mix of scholarly and nonscholarly serials (including magazines, journals, newsletters, newspapers, and directories, in all subject areas). ${ }^{5}$ The most common reasons for title changes found in these studies were for subject changes, corporate changes, language changes, editorial changes, frequency changes, and function changes. There has been little ongoing work aside from the author's on this topic.

\section{Comparisons of Academic and Nonacademic Serials}

Comparisons of academic and nonacademic serials were made by two authors, with a third offering some related insights. Shadle comments on differences he observed between scholarly journals and popular magazines and questioned why the same cataloging rules are used for resources with different purposes and different audiences. ${ }^{6}$ He noted that popular magazines are diverging in publishing practices between print and online and speculated if future online academic journals will begin to assume some of the characteristics of current online popular magazines. Headley compares concerns about serials in public and academic libraries, observing that both have issues with title changes, yet academic libraries often have the diverse staffing needed to deal with the various serial issues more effectively than public libraries. ${ }^{7}$ Jones provides some related insights on the different title-change patterns found when comparing disciplines, noting that scientific serials showed a higher rate of title changes than the social science and humanities serials. ${ }^{8}$

\section{Concept of a Work}

The concept of a work in the modern catalog was the focus of a special issue of Cataloging and Classification Quarterly. ${ }^{9}$ Various views have been expressed about the more specific concept of a serial work. Kuhagen, for example, believes that users' needs in finding and selecting serials would be best supported if serials with title changes were treated as single works, whereas mergers and splits could be treated as different works. ${ }^{10}$ Antelman suggests that neither the cataloger nor the library user would see a new work in the records created by cataloging rules. ${ }^{11}$ She proposes grouping records for related serials in the library catalog into bibliographic families. Another suggestion, by Adams and Santamauro, is to abolish successive entry cataloging and instead create umbrella records for "superworkspressions." 12 New records would be created for changes in content. The authors acknowledge, however, that knowing when content has changed sufficiently to identify a new superworkspression may be difficult.

The abstract nature of a work is described in the following excerpt from the Functional Requirements for Bibliographic Records (FRBR) report:

A work is an abstract entity; there is no single material object one can point to as the work. We recognize the work through individual realizations or expressions of the work, but the work itself exists only in the commonality of content between and among the various expressions of the work. Because the notion of a work is abstract, it is difficult to define precise boundaries for the entity. The con- 
cept of what constitutes a work and where the line of demarcation lies between one work and another may in fact be viewed differently from one culture to another. ${ }^{13}$

\section{Strategies for Identifying New Works for Serials with Title Changes}

Strategies for identifying new works for serials with title changes were not specifically discussed in the literature. However, the more general topic of cataloging strategies for title changes has been discussed at length, with much written about the pros and cons of the various mechanisms that can be used to determine when new records should be created when titles change. However, a clear correlation has not be demonstrated between the use of specific mechanisms and the identification of what would be seen as a new work. Three conventions have been used historically for cataloging serials with title changes, as described by Hirons:

- Earliest entry: all changes are kept on a single record with the description based on the earliest issue and title changes, etc. recorded in notes;

- Latest entry: all changes are kept on a single record with description based on the latest (most recent) issue and earlier titles, etc. given in notes;

- Successive entry: a new record is made for each title or other major change (e.g., main entry); description is based on the latest issue (AACRI) or the earliest issue (AACR2). ${ }^{14}$

The discussion that follows begins with the history of title-change rules and then considers the pros and cons of latest-entry and successive-entry cataloging. Jones reviewed the history of title change rules in a presentation at the 2016 American Library Association Midwinter Meeting. Throughout the presentation, he offered insights into why the rule makers did what they did, noting that the boundary of the work changed as cataloging conventions changed. ${ }^{15} \mathrm{In}$ the 1800s, the book catalog was in use, for which it worked best to have all title changes recorded in one place under the earliest entry. With the beginning of rule making by committee in 1908, the card catalog had come into being and dual cataloging practices were implemented by the British and the Americans. The British preferred earliest-entry cataloging and the Americans instituted latest-entry cataloging to accommodate users who were thought to be more likely to look under the current title than an earlier title. In 1953, Lubetzky began advocating for successive-entry cataloging because he believed users were more likely to search for the title of the specific volume they were seeking rather than by a later or earlier title, and in 1961 the Paris principles endorsed successive entry cataloging. Successive entry worked well with the card catalog, reducing the need to redo cards each time a title changed.

The Anglo-American Cataloging Rules (AACR), published in 1967, prescribed successive-entry cataloging, but as Jones noted it was not until 1971 that the Library of Congress switched from latest-entry to successive-entry, pressured by the need to expedite serials cataloging. AACR2, published in 1978, continued to prescribe successive-entry for serials whereas an update in 2002 prescribed latest-entry for integrating resources. There was an attempt in 1988 to bring back latest-entry for serials as better suited for the online catalog, which had replaced the card catalog in many libraries, but the effort did not succeed because of the numerous records that had been created under successive-entry and also the requirements of the ISSN (International Standard Serial Number) system. Jones concluded his review of serialtitle changes through the ages by submitting that the use of dual cataloging conventions, one for serials and one for integrating resources, has caused the question "What is a work?" to remain in tension. ${ }^{16}$

Latest- versus successive-entry cataloging was the theme of a symposium organized by Mary Curran, editor of the resulting collection of articles. ${ }^{17}$ Points from two of the contributors, Baia and Randall, are discussed here. ${ }^{18}$ Baia, a proponent of latest-entry, lists the advantages of latest-entry, along with responses to common criticisms. Randall, a former proponent of latest-entry, describes how his thinking eventually changed. Both Randall and Baia report that their respective institutions finally abandoned latest-entry for successive-entry cataloging (Northwestern University in 1996 and the University of Colorado in 1999, respectively) because of the lack of synchronization with other libraries' records in their library systems. Another factor was the conflicting OCLC (Online Computer Library Center) requirement of successive-entry records for libraries wanting to maintain their holdings in WorldCat. Some commonly recognized advantages and disadvantages of latest-entry are noted below. An advantage for latest-entry is generally seen as a disadvantage for successive-entry and vice versa.

\section{Advantages of Latest-Entry Cataloging}

- Satisfied users-A single record is what users would logically expect, according to Baia. A user survey, Randall notes, showed that latest entry led users to the desired information more easily.

- Ease of updating - In the online environment, the ease of updating makes successive-entry obsolete, according to both Baia and Randall.

- Fewer duplicates retrieved-Successive-entry results in duplicate search results because of repetitive added entries in the multiple records, Baia notes. ${ }^{19}$ 


\section{Disadvantages of Latest-Entry Cataloging}

- Massive recataloging-Response: Existing successive-entry records, Baia suggests, would not have to be converted to latest-entry except for the most recent record.

- Long and complex records-Response: A study noted by Baia showed the majority of serial records that represented non-US government documents were not overly long, with most records including only one title change. Randall, however, observes that records become more complex when multiple title changes are combined with corporate body main entry changes.

- Different title than expected-Response: If titles are listed chronologically with dates, Baia proposes, it will be clear why the record was retrieved. ${ }^{20}$

\section{International Cataloging Standards}

The international harmonization of cataloging rules was the focus of a "Meeting of Experts" in 2000. ${ }^{21}$ The primary purpose of the meeting was to discuss continuing resource cataloging practices, with the goal of facilitating more extensive sharing of catalog records. Three groups participated in the harmonization efforts: the Joint Steering Committee (for $A A C R$ ), the $\operatorname{ISBD}(\mathrm{S})$ (International Standard Bibliographic Description for Serials) Working Group, and the ISSN Manual Revision Committee. One of the objectives was to have "everyone, regardless of the cataloging rules being followed, make the same decision about the need for a new serial record." Another goal was to create rules for title changes that would meet the following requirements: recognize only significant title changes, recognize deliberate changes in the work, and enable a wide variety of people working with serials, including acquisitions and check-in staff, to understand the rules.

The ISSN standards play an important role in serials cataloging. Reynolds describes how the simultaneous rule revisions in 2002-03 between $A A C R 2, \operatorname{ISBD}(\mathrm{S})$, and the ISDS Manual synchronized the rules for major and minor changes that from then on determined when a new record and new ISSN should be created. ${ }^{22}$ The major and minor change rules have carried over to $R D A$. However, even with the new synchronization, applying the ISSN rules is still challenging because different cataloging rules are followed for non-ISSN elements by many of the larger ISSN centers, as specified by the center's affiliated institution or cooperative program. Reynolds notes that publisher preferences have not helped in solving the problem because publishers have differing views on title-change policies, as described below:
- Some publishers seem to want every change-no matter how minute- to be assigned a new ISSN, either because of how they use ISSN internally, or because their title changes are intended to signal other changes such as a new editor, new ownership, or a new editorial direction.

- Other publishers seem to want to keep the same ISSN forever, giving the impression that they feel ownership of a particular ISSN is part of their "brand."

A call has been issued by the ISSN International Centre for revision of the current ISSN standard, which dates from 2007. Topics to be discussed include

- title changes, including major and minor change rules; ${ }^{24}$

- whether ISSN should be assigned to a "family" of serials that would encompass all title changes or even all related editions;

- clarification of which digital editions or formats should be assigned their own ISSN;

- alignment between mandatory ISSN metadata and ONIX metadata; and

- expansion of information about use of ISSN with other identification and linking systems. ${ }^{25}$

\section{Future of Serials Cataloging}

The future of serials cataloging was discussed during an interactive session between four serials cataloging experts, moderated by Erik Bergstrom. Some of their comments follow:

- Publishers_-"RRR [Regina Romano Reynolds]: . . . On the one hand, I see publisher descriptions as likely forming the basis of future library descriptions. On the other hand, having publishers contribute directly to shared databases constructed according to cataloging codes and formats will likely be problematic." ${ }^{\text {26 }}$

- Continuing resources-“RRR: . . . Since just about everything will be a continuing resource, there will still be a need for ISSN to help track those transactions [of library expenditures]." ${ }^{, 27}$

- Popular versus academic serials_-"SS [Steven Shadle]: ... One of the things I think about is why we are using the same set of rules to catalog different kinds of resources when they are actually different items that serve different purposes, different needs, and different audiences. . . . I know the newspaper community has developed their own set of practices, and the context I am coming from is the scholarly journal because I work in an academic environment. In that environment the citation is of critical importance. 
But when we talk about the future, I think the questions that have to do with magazines are interesting because popular magazines are where we have seen a lot of diverging between print and online in terms of publishing practices. I wonder whether future online academic journals will look more like current online popular magazine." ${ }^{\text {'S }}$

- Different rules for different materials_-"EB [Erik Bergstrom]: Shana, should we be using the same set of rules to catalog a journal, a newspaper, a magazine, or a blog? . . SLM [Shana L. McDanold]: I think we have to look at what are we trying to accomplish? ... What are we creating, why are we creating it, and for whom? If the ultimate goal, no matter the content, is to provide access to that content, I think there is going to be that base-level content that requires base-level metadata across the board, whether it is a book or a magazine or a newspaper or a scholarly journal. ... Beyond the base level of identification ... what you add to that really should not be locked down." ${ }^{29}$

- Base level-“LH [Les Hawkins]: I think that [baseline treatment] is the only way we can get all the different providers of metadata to contribute. We need to focus in on what is needed for the base level of identification to make this possible. We tried with the CONSER Standard Record to pare down to the basic required elements, and I think it was successful." ${ }^{30}$

- Concept of the work-"RRR: . . I I am concerned that all of this wonderful potential linking may bog down if we fragment the concept of the work too finely. In other words, I think we should try to cover multiple variations on the work theme with one identification as opposed to proliferating these unique identi[t]ies, which then cannot serve as the hub for all of this other metadata because people are linking to 10 different unique identities rather than one."31

Bibliographic Framework Initiative (BIBFRAME), the projected replacement for MARC, is a topic of particular interest relevant to the future of cataloging. Balster describes work by the UCLA Continuing Resources Study Group, which has focused recently on issues related to converting serial records from MARC to BIBFRAME. ${ }^{32}$ In a presentation at the 2016 American Library Association Annual Conference, Balster described problems that have been identified by the Study Group in test conversions of serial records to BIBFRAME. ${ }^{33}$ One problem noted is that there is no explicit support in BIBFRAME for changes over time within a single work, including changes in title (minor title changes), publisher, and frequency. BIBFRAME treats minor title changes as multiple main titles, the equivalent of multiple MARC 245 fields, but in MARC these are coded as variant titles in the 246 field. Balster notes that the BIBFRAME treatment of minor title changes is more in line with $R D A$, which treats minor title changes as later titles proper. Balster concludes by suggesting that BIBFRAME provides an opportunity to investigate the reasons for doing what we do and to change practices to take advantage of what the linked data environment has to offer.

\section{Method}

\section{Conceptual Framework}

The study's purpose was to compare the characteristics of academic and nonacademic serials with title changes, and to develop a collective strategy for identifying new works for these serials. To compare these two types of serials, two sets of data were needed, the first relevant to academic serials and the second pertaining to nonacademic serials. Data concerning academic serials were collected in a previous study, but no corresponding data were available for nonacademic serials. It was thus determined to collect matching information for the nonacademic serials, including data on: reasons for title changes, sources of information, subcategories explaining title changes, and evidence for new serial works. It was further determined to use the collected data to draw comparisons between these two distinct serial subpopulations.

The research was intended as a descriptive and exploratory study of the two serial subpopulations. The $R D A$ definitions of a serial and a work were used. Thus a serial was defined as "a resource issued in successive parts, usually bearing numbering, that has no predetermined conclusion (e.g., a periodical, a monographic series, a newspaper)" and a work was defined as "a distinct intellectual or artistic creation (i.e., the intellectual or artistic content)." ${ }^{\text {34 }}$

To meet the study's objectives, answers were sought to four research questions correlating with the four areas investigated in the previous study of academic serials:

1. Reasons for title changes-What are the reasons for title changes in academic and nonacademic serials?

2. Sources of information-How does textual content compare with title words as a source of information in determining reasons for title changes in academic and nonacademic serials?

3. Subcategories explaining title changes-How can reasons for title changes be subcategorized for academic and nonacademic serials?

4. Evidence for new serial works-Which subject and function subcategories represent changes that provide evidence for new serial works in academic and nonacademic serials? 


\section{Samples}

Two samples were used in the study, one from the subpopulation of academic serials with title changes and one from nonacademic serials. The sample of academic serials was taken in a previous study and the sample of nonacademic serials was taken in the current study. The samples were limited to English-language serials because the study was seen as an exploratory study and a starting point for further studies, if needed, including studies of non-English-language serials. Serials were chosen that were accessible to the researcher rather than by random selection because of the potential difficulty in gaining access to serials located out-ofstate or for which physical or electronic access might not be allowed by the holding library. Access to complete issues was required, as explained below, and thus interlibrary loan was not seen as an option because libraries generally do not lend journal volumes. Details concerning the two samples follow.

\section{Academic Serials}

The sample of nonacademic serials with title changes was taken from the JSTOR online database of full-text digitized back issues of academic journals. ${ }^{35}$ The database provides information on previous titles, mergers, and splits, allowing titles to be identified for which a title change has occurred. Serials from four JSTOR collections were included in the sample: Arts and Sciences I, Arts and Sciences II, Arts and Sciences III, and Life Sciences. These collections were chosen because the researcher had institutional access to the collections and also because they represented a range of subject areas. Non-English serials were excluded, as were serials consisting of splits or mergers. Serials for which no explanation of the title change was found in the text were also excluded, leaving 120 serials in the final sample, just under half (44.8 percent) of the initially qualifying serials with title changes.

\section{Nonacademic Serials}

The sample of nonacademic serials with title changes was obtained by using the Ulrich's database as the starting point. Ulrich's was chosen because of the database's comprehensive nature and the ability to search for serials within specific categories. The database provides a history of each periodi$\mathrm{cal}$, including the identification of former titles, incorporated titles, and mergers. Ulrich's includes data relevant to all types of periodicals and in all subject areas, as indicated in the following description of the database:

Ulrich's is the authoritative source of bibliographic and publisher information on more than 300,000 periodicals of all types [including] academic and scholarly journals, Open Access publications, peerreviewed titles, popular magazines, newspapers, newsletters and more from around the world. It covers all subjects, and includes publications that are published regularly or irregularly and that are circulated free of charge or by paid subscription. ${ }^{36}$

The following conditions were applied in the initial Ulrich's search to obtain a preliminary list of serials to sample: "English" (language of text), "magazine" (serial type), and a "Magazines for Libraries" review. The English limitation was applied to correspond with the language limitation in the previous study of academic serials. It was determined that limiting the search to magazines would yield titles that were mostly nonacademic, with "trade" or "consumer" as the main content types. Trade serials contain news and items of interest to a particular trade, whereas consumer serials are those sold to the general public and usually intended for a nonprofessional audience. It was, finally, determined that limiting the sample to serials with a review would reduce the results to a more manageable size and potentially to titles more commonly held within library collections.

The strategy described above resulted in a list of 3,558 titles. Further exclusions were made to limit the sample to serials with title changes, indicated by "null" in the history column (1,709), and to serials that were not incorporated or merged, indicated also in the history column $(1,397)$. Titles that were merged, split, or absorbed were already considered as new works and not in need of further analysis. Microsoft Excel files were created from downloaded information for the qualifying titles.

The author's next challenge was how to obtain access to the identified serials. From a presample of twenty-five serials, it was determined that of the eighteen with a title change, eleven were available in a major library within the researcher's home state. The first or earliest issue of five of the serials was available at the Merrill-Cazier Library, Utah State University (MCL), easily accessible to the researcher. Access issues necessitated working with the serials in the MCL and going beyond that only if needed.

Of the 1,397 qualifying serials identified in Ulrich's, records for 574 were found in the MCL online catalog, but the first issue was available in the library for only 261 of these serials. The first issue was needed to determine whether an explanation of the title change was provided. Eighteen additional serials were excluded for various reasons (twelve with no title change, four print/online duplicates, one non-English, and one that was in the previous sample of academic serials), leaving 243 serials.

The final step was to examine the first issue of each of the 243 serials to determine whether an explanation of the title change was given. A total of 113 serials lacked an explanation, leaving 130 serials in the final sample, just over 
half (53.5 percent) of the initially qualifying serials. The size of the resulting sample was comparable to the 120 serials in the previous sample of academic serials and was determined to be sufficient. Of note was the fact that only one title overlapped with a title in the previous sample, confirming that the current sample was indeed unique. The sample included print, electronic, and microfilm serials, depending on which format was available for a particular title. A Microsoft Word table was created from the original Excel files for the 130 titles (see appendix A).

\section{Limitations of the Samples}

Because the samples were not randomly selected from the respective subpopulations of academic and nonacademic serials, generalizations of the study's findings will be limited. The sample of academic serials contained a variety of academic serials, but it was limited to those in the specific JSTOR collections that were sampled. The sample of non academic serials consisted mainly of trade and consumer magazines, thus excluding other potential types of nonacademic serials, plus serials that were not available in the MCL. The English-language constraint in both samples means generalizations will be limited to serials in the English language.

Another limitation was that JSTOR and Ulrich's entries were used without investigating how decisions for creating new entries for title changes were made in the respective databases. The titles listed were not verified against a cataloging code to determine whether recognizing the new title corresponded with specific cataloging rules. If a new title was questionable, WorldCat or the OCLC records in the MCL online catalog were checked to clarify the title-change history and the dates for the old and new titles.

\section{Procedure for Identifying Characteristics of Title Changes for Serials}

Procedures were developed for gathering the required information in the following four areas noted above: reasons for title changes, sources of information, subcategories explaining title changes, and evidence for new serial works. The procedures are explained below and replicate the steps followed in the previous study of academic serials.

\section{Reasons for Title Changes}

The data collection began by seeking an answer to the first research question: what are the reasons for title changes in academic and nonacademic serials? Because data were already available for the academic serials, the data collection focused on the nonacademic serials. Reasons for title changes were examined in the sampled serials using two sources of information: textual content and title words. The steps in the data collection are outlined below.

\section{Using Textual Content as the Source}

In this phase of the data collection, reasons for title changes were determined from statements appearing in the sampled serials, following the steps below:

- Analyzed textual content. The first issue of each serial following the title change was examined. Other issues were also occasionally examined, especially if electronically available, when clarification was needed or if the first issue lacked explanation. The beginning pages of the issue were checked, and any text providing a reason for the title change was photocopied. The following information was generally not copied: simple statements that the title had changed; instructions to authors; or descriptions of changes in editors, publishers, cover design, typeface, layout, number of pages, or the serial's medium of publication.

- Assigned title-change categories. A table was created listing all titles in the sample along with the text explaining why the title changed. The explanations were classified using the six categories devised in the previous study: S-subject change, U-function change, C-corporate change, G-geographic change, Q-frequency change, and F-title word-format change. The categories are described in detail in appendix B (column 2), along with examples. Relevant category codes were entered in appendix A (column 5) for each serial. If a title change occurred for more than one reason, the serial was coded under each of the reasons.

\section{Using Title Words as the Source}

In this phase of the data collection, reasons for title changes were determined from word changes between the old and new titles of the sampled serials, following the steps below:

- Analyzed title words. The words in the old and new title of each serial were compared for evidence to explain the title change. Words occurring in title qualifiers were not analyzed.

- Assigned title-change categories. Word changes in the titles were classified using the same six categories as in the previous study: s-subject change, u-function change, c-corporate change, g-geographic change, $q$-frequency change, and f-title word-format change. The kinds of change required to assign a specific category are described in appendix B (column 3), along 
with examples. Though logic was used in assigning the categories, changes in title words may have occurred for reasons other than what might be expected. A word may have been dropped from a title, for instance, not because the corresponding subject was no longer covered, but simply to shorten the title. Relevant category codes were entered in appendix A (column 6) for each serial. If a title change occurred for more than one reason, the serial was coded under each of the reasons.

\section{Sources of Information}

Next, data were collected concerning the second research question: how does textual content compare with title words as a source of information in determining reasons for title changes in academic and nonacademic serials? Data were collected on the nonacademic serials to supplement what was already known about the academic serials. The category codes in appendix A were used to create two tables, the first showing the reasons for title changes discerned from the combined sources and the second showing unique reasons from the individual sources. Two counts were tabulated from the data in the tables: the number of all reasons for title changes, by category, from the combined sources and the number of unique reasons for title changes, by category, from a single source.

\section{Subcategories Explaining Title Changes}

The third research question was, how can reasons for title changes be subcategorized for academic and nonacademic serials? Data were collected on the nonacademic serials to complement what was already known about the academic serials using textual content as the source. The descriptions of why titles changed, identified above, were grouped into subcategories by following the steps below:

- Alphabetical lists were created of all descriptions of why titles changed within each of the six categories noted above.

- A table was built for each of the six categories wherein the descriptions could be grouped into subcategories by wording and intent, with some rewording where needed to create consistency for better grouping.

$\circ$ Existing subcategories, identified in the previous study of academic serials, were used when applicable.

- New subcategories were created as needed

- Descriptions that referred to more than one type of change were grouped under the subcategory corresponding with the first change mentioned unless a subsequently described change was more specific.

\section{Evidence for New Serial Works}

The fourth research question was, which subject and function subcategories represent changes that provide evidence for new serial works in academic and nonacademic serials? Data were already available for the academic serials, so the data collection focused on the nonacademic serials, using textual content as the source. The subcategories identified above were grouped according to the expected value of the change(s) represented by each subcategory in identifying a new work. A level of evidence was then assigned to each subcategory using the FRBR guidelines for modified works to provide the foundation for the process.

The FRBR guidelines for modified works, developed by the IFLA Study Group on the Functional Requirements for Bibliographic Records, were used in determining how to rank the subcategories. The guidelines state, "By contrast, when the modification of a work involves a significant degree of independent intellectual or artistic effort, the result is viewed, for the purpose of this study, as a new work. ${ }^{\cdot 37}$ The guidelines thus require that a significant degree of independent intellectual or artistic effort has taken place. This suggests that a serial with a title change must be analyzed in two areas: kind of change and significance of change.

Subject change seemed to be a kind of change that would help recognize a new work because a serial's intellectual content would change (e.g., broadening content or adding new areas of coverage). A function change also seemed to qualify because of the change in the kind of intellectual content provided (e.g., a change from a newsletter to a scholarly journal).

Identifying significant subject and function changes was more difficult. To accomplish this, three levels (high, medium, low) were used to rank the subject and function subcategories' significance in identifying a new work. The levels were assigned according to the degree of change represented by the subcategory. Thus a change in the overall content would be a high-level change whereas the addition of a book review section to a serial would be a low-level change.

The steps followed in ranking the subject and function subcategories and then coding the serials were as follows:

1. A level was assigned (high, medium, low) to each identified subject and function subcategory.

2. The assigned levels were added to the subject and function subcategory tables.

3. The level assigned to each serial for each relevant subject and function change was noted in appendix A (column 7).

4. The serials for which a high-level subject or function change occurred were noted in appendix A (column 7).

5. "None" was entered in appendix A (column 7) if no subject or function change occurred. 
Table 1. All Reasons for Title Changes from Textual Content in Academic Versus Nonacademic Serialsi

\begin{tabular}{|c|c|c|c|c|}
\hline Reason for Title Change & \multicolumn{2}{|c|}{ Academic } & \multicolumn{2}{|c|}{ Nonacademic } \\
\hline Subject change & $60(80)$ & 50.0 & $62(77)$ & 47.7 \\
\hline Corporate change & 22 & 18.3 & 8 & 6.2 \\
\hline Geographic change & $7(8)$ & 5.8 & 3 & 2.3 \\
\hline Title word format change & $17(21)$ & 14.2 & $28(33)$ & 21.5 \\
\hline Total & $187(247)$ & & 197 (269) & \\
\hline
\end{tabular}

i. This table (columns 1-3) is based on an original paper published in Taylor \& Francis: Mavis B. Molto, "Characteristics of Serial Title Changes and Recognition of New Serial Works: Theoretical and Practical Implications,” Serials Review 37, no. 4 (2011): 280, table 3. Nonacademic serials data were obtained from appendix A.

ii. Parenthesized numbers include multiple occurrences of a particular type of change (e.g., a subject change) for the same title.

\section{Results}

Findings were compiled from the collected data in the following areas, corresponding with the four research questions above: (1) Reasons for title changes, (2) Sources of information, (3) Subcategories explaining title changes, and (4) Evidence for new serial works.

\section{Reasons for Title Changes}

What are the reasons for title changes in academic and nonacademic serials? To answer this question, two sources of information were used: textual content and title words. The reasons found in each source were tabulated in two different ways: first by all reasons found for each title change, and then by the primary reason for each title change. Reasons were classified according to the six title-change categories noted above: subject change, function change, corporate change, geographic change, frequency change, and title-word format change. For some serials, there was just one reason for the title change and for others there were multiple reasons. Findings from the data collection are reported below.

\section{Findings for All Reasons, from Textual Content}

Table 1 provides a summary of all reasons found for the title changes, including multiple reasons for a single title change (e.g., a subject change as well as a function change), using textual content as the source. Comparative findings for the academic and nonacademic serials are shown in table 1 in an unordered listing by title-change category. Multiple reasons falling in the same category for a specific serial (e.g., two subject changes for the same serial) were counted only once, with a parenthesized number showing the count when including the multiple reasons.
Example: Title XYZ has had a title change for which three reasons were found: a subject change, a function change, and a frequency change in the serial. All three reasons would be included in the counts in table 1 .

\section{Findings for Primary Reasons, from Textual Content}

Table 2 provides a summary of the primary reasons for title changes, with textual content as the source. A primary reason was defined as "the reason for a title change having most relevance in identifying a new work when using the FRBR guidelines for recognizing new works." The primary reason ranked highest among all reasons found for a particular title change according to the following priorities (from high to low): subject change, function change, corporate change, geographic change, frequency change, and title-word format change. A subject change was given first priority as it involves a change in intellectual content. A function change was given second priority because a change in function involves a change in the kind of intellectual content. The remaining types of changes were prioritized somewhat arbitrarily according to the expected effect of the change on the content of the serial. Comparative findings for the academic and nonacademic serials are shown in table 2 in an unordered listing by title-change category.

Example: Title XYZ, referred to above, has had a title change for which three reasons were found: a subject change, a function change, and a frequency change. The primary reason is the subject change because it has the highest rank in the prioritized list. Just the subject change would be included in the counts in table 2.

\section{Findings for All Reasons, from Title Words}

Table 3 provides a summary of all reasons found for the title changes, including multiple reasons for a single title 
Table 2. Primary Reasons for Title Changes from Textual Content in Academic Versus Nonacademic Serials $i$

\begin{tabular}{|c|c|c|c|c|}
\hline \multirow[b]{2}{*}{ Reason for Title Change } & \multicolumn{2}{|c|}{ Academic } & \multicolumn{2}{|c|}{ Nonacademic } \\
\hline & Primary Reasons & $\%$ of Serials $(N=120)$ & Primary Reasons & $\%$ of Serials $(N=130)$ \\
\hline Subject change & 60 & 50.0 & 62 & 47.7 \\
\hline Function change & 37 & 30.8 & 54 & 41.5 \\
\hline Corporate change & 6 & 5.0 & 2 & 1.5 \\
\hline Geographic change & 3 & 2.5 & 1 & 0.8 \\
\hline Frequency change & 8 & 6.7 & 0 & 0.0 \\
\hline Title word format change & 6 & 5.0 & 11 & 8.5 \\
\hline Total & 120 & 100.0 & 130 & 100.0 \\
\hline
\end{tabular}

Table 3. All Reasons for Title Changes from Title Words in Academic Versus Nonacademic Serialsi

\begin{tabular}{|c|c|c|c|c|}
\hline Reason for Title Change & \multicolumn{2}{|c|}{ Academic } & \multicolumn{2}{|c|}{ Nonacademic } \\
\hline Subject change & 69 & 57.5 & 93 & 71.5 \\
\hline Corporate change & 34 & 28.3 & 18 & 13.8 \\
\hline Geographic change & 26 & 21.7 & 26 & 20.0 \\
\hline Title word format change & $60(64)$ & 50.0 & $78(92)$ & 60.0 \\
\hline Total & $263(327)$ & & $258(350)$ & \\
\hline
\end{tabular}

i. This table (columns 1-3) is based on an original paper published in Taylor \& Francis: Mavis B. Molto, "Characteristics of Serial Title Changes and Recognition of New Serial Works: Theoretical and Practical Implications," Serials Review 37, no. 4 (2011): 280, table 5. Nonacademic serials data were obtained from appendix A of the current study.

ii. Parenthesized numbers include multiple occurrences of a particular type of change (e.g., a subject change) for the same title.

change (e.g., a subject change as well as a function change), using title words as the source. Comparative findings for the academic and nonacademic serials are shown in table 3 in an unordered listing by title-change category. Multiple reasons falling in the same category for a specific serial (e.g., two function changes for the same serial) were counted only once, with a parenthesized number showing the count when including the multiple reasons.

\section{Findings for Primary Reasons, from Title Words}

Table 4 provides a summary of the primary reasons for title changes, with title words as the source. Primary reasons for titles changes were determined, as above, according to relevance in identifying a new work. The primary reason was the reason with the highest rank among all reasons found for a particular title change, according to the following priorities: subject change, function change, corporate change, geographic change, frequency change, and title-word format change. Comparative findings for the academic and nonacademic serials are shown in table 4 in an unordered listing by title change category.

\section{Sources of Information}

How does textual content compare with title words as a source of information in determining reasons for title changes in academic and nonacademic serials? To address this issue, two sets of data were collected: data from the combined sources and data specific to a single source. Findings are reported below.

\section{Findings Using Combined Sources}

Table 5 summarizes the findings for academic serials versus nonacademic serials when using information from the combined sources (i.e., textual content and title words) to identify all possible reasons for title changes. Counts are reported within each of the six title-change categories previously noted. 
Table 4. Primary Reasons for Title Changes from Title Words in Academic Versus Nonacademic Serialsi

\begin{tabular}{|c|c|c|c|c|}
\hline \multirow[b]{2}{*}{ Reason for Title Change } & \multicolumn{2}{|c|}{ Academic } & \multicolumn{2}{|c|}{ Nonacademic } \\
\hline & Primary Reasons & $\%$ of Serials $(N=120)$ & Primary Reasons & $\%$ of Serials $(N=130)$ \\
\hline Subject change & 68 & 56.7 & 93 & 71.5 \\
\hline Corporate change & 9 & 7.5 & 9 & 6.9 \\
\hline Geographic change & 2 & 1.7 & 0 & 0 \\
\hline Title word format change & 5 & 4.2 & 9 & 6.9 \\
\hline Total & 120 & $100.1^{\mathrm{ii}}$ & 130 & $99.9^{\mathrm{ii}}$ \\
\hline \multicolumn{5}{|c|}{$\begin{array}{l}\text { i. This table (columns 1-3) is based on an original paper published in Taylor \& Francis: Mavis B. Molto, "Characteristics of Serial Title Changes and } \\
\text { Recognition of New Serial Works: Theoretical and Practical Implications," Serials Review 37, no. } 4 \text { (2011): 281, table 6. Nonacademic serials data } \\
\text { were obtained from appendix A in the current study. } \\
\text { ii. Total is greater or less than } 100 \text { due to rounding. }\end{array}$} \\
\hline
\end{tabular}

Table 5. Reasons for Title Changes from Combined Sources in Academic Versus Nonacademic Serials'

\begin{tabular}{|c|c|c|c|c|}
\hline \multirow[b]{2}{*}{ Reason for Title Change } & \multicolumn{2}{|c|}{ Academic } & \multicolumn{2}{|c|}{ Nonacademic } \\
\hline & $\begin{array}{l}\text { Reasons from Combined } \\
\text { Sources }{ }^{\mathrm{ii}}\end{array}$ & $\%$ of Serials $(N=120)$ & $\begin{array}{l}\text { Reasons from Combined } \\
\text { Sources }\end{array}$ & $\%$ of Serials $(N=130)$ \\
\hline Subject change & 80 & 66.7 & 100 & 76.9 \\
\hline Function change & 81 & 67.5 & 97 & 74.6 \\
\hline Corporate change & 48 & 40.0 & 23 & 17.7 \\
\hline Geographic change & 28 & 23.3 & 26 & 20.0 \\
\hline Frequency change & 23 & 19.2 & 7 & 5.4 \\
\hline Title word format change & 64 & 53.3 & 82 & 63.1 \\
\hline Total & $324^{\mathrm{iii}}$ & 270.0 & $335^{\mathrm{iv}}$ & 257.7 \\
\hline
\end{tabular}

i. This table (columns 1-3) is based on an original paper published in Taylor \& Francis: Mavis B. Molto, "Characteristics of Serial Title Changes and Recognition of New Serial Works: Theoretical and Practical Implications," Serials Review 37, no. 4 (2011): 282, table 7. Nonacademic serials data were obtained from textual content in the sampled nonacademic serials.

ii. If multiple reasons were found for a title within the same category (e.g., two subject changes), only one occurrence was counted.

iii. Total reasons $=450$ when including the double occurrence of duplicate reasons (126) found in both the textual content and the title words.

iv. Total reasons $=455$ when including the double occurrence of duplicate reasons (120) found in both the textual content and the title words.

Table 6. Reasons for Title Changes Unique to a Single Source in Academic Versus Nonacademic Serials ${ }^{i}$

\begin{tabular}{|c|c|c|c|c|}
\hline \multirow[b]{2}{*}{ Reason for Title Change } & \multicolumn{2}{|c|}{ Academic } & \multicolumn{2}{|c|}{ Nonacademic } \\
\hline & $\begin{array}{l}\text { Reasons Unique to Textual } \\
\text { Contenti }\end{array}$ & Reasons Unique to Title Words & $\begin{array}{l}\text { Reasons Unique to Textual } \\
\text { Content"i }\end{array}$ & Reasons Unique to Title Words \\
\hline Subject change & 11 & 20 & 7 & 38 \\
\hline Function change & 19 & 17 & 58 & 5 \\
\hline Corporate change & 14 & 26 & 5 & 15 \\
\hline Title word format change & 4 & 47 & 4 & 54 \\
\hline Total & 61 & 137 & 77 & 138 \\
\hline
\end{tabular}

i. This table (columns 1-3) is based on an original paper published in Taylor \& Francis: Mavis B. Molto, "Characteristics of Serial Title Changes and Recognition of New Serial Works: Theoretical and Practical Implications,” Serials Review 37, no. 4 (2011): 282, table 8. Nonacademic serials data were obtained from textual content in the sampled nonacademic serials.

ii. If multiple reasons were found for a title within the same category (e.g., two subject changes), only one occurrence was counted. 


\section{Findings Using a Single Source}

Table 6 summarizes the findings for academic serials versus nonacademic serials when using information from a single source (i.e., only textual content or only title words) to identify unique reasons for title changes found only in that source. Counts are reported within each of the six titlechange categories previously noted.

\section{Subcategories Explaining Title Changes}

How can reasons for title changes be subcategorized for academic and nonacademic serials? To address this issue, the descriptions of why titles changed, taken from the textual content of the serials, were grouped into subcategories to more specifically describe the reasons for the title changes. Tables 7-9 list the subcategories identified for the academic and nonacademic serials, showing separate counts for each. Table 7 lists the subject subcategories, table 8 lists the function subcategories, and table 9 lists the corporate, geographic, frequency, and title word format subcategories.

\section{Evidence for New Serial Works}

Which subject and function subcategories represent changes that provide evidence for new serial works in academic and nonacademic serials? To answer this question, each subject and function subcategory assigned above, from descriptions in the textual content, was ranked according to the magnitude of evidence provided for a new work: high, medium, or low. Table 7 lists the subject subcategories according to the three levels, and table 8 lists the function subcategories according to the same three levels, with each table showing separate subcategory counts for the academic and nonacademic serials.

\section{Comparison of Academic and Nonacademic Serials}

What follows are comparisons between academic and nonacademic serials with title changes. The study was not designed to prove that significant differences exist between the two serial subpopulations because randomly selected samples would have been required to provide the needed evidence. The intent was merely to use the available data to identify preliminary differences that could later be tested further if needed. The findings from the data collection are compared below, showing the similarities and differences between academic and nonacademic serials with title changes. Comparisons are made within the four areas described above: (1) reasons for title changes, (2) sources of information, (3) subcategories explaining title changes, and (4) evidence for new serial works.

\section{Reasons for Title Changes in Academic versus Nonacademic Serials}

How do the reasons for title changes compare for academic serials versus nonacademic serials? To compare the two subpopulations, the data reported in tables 1-4 above were used. Tables 1 and 2 provide counts of title-change explanations found in the textual content of the serials whereas tables 3 and 4 provide counts of explanations derived from an examination of the title words. The academic and nonacademic serials had both similarities and differences in the reasons found for title changes. Comparisons between the two subpopulations are made below, first using textual content as the source and then using title words as the source.

\section{Similarities (from textual content)}

- Overall reasons most frequently found for a title change-academic (subject and function changes), nonacademic (same)

- Subject changes found overall—academic (50.0 percent), nonacademic (47.7 percent)

- Subject change as the primary reason for a title change-academic (50.0 percent), nonacademic (47.7 percent)

\section{Differences (from textual content)}

- Function changes found overall—academic (53.3 percent), nonacademic (70.8 percent)

- Function change as the primary reason for a title change-academic (30.8 percent), nonacademic (41.5 percent)

\section{Similarities (from title words)}

- Average number of reasons found for a title changeacademic (2.19), nonacademic (1.98)

- Overall reasons most frequently found for a title change-academic (subject, function, and title word format changes), nonacademic (same)

- Primary reason most frequently found for a title change-academic (subject change), nonacademic (same)

- Primary reason next most frequently found for a title change-academic (function change), nonacademic (same) 
Table 7. Subject Change Subcategories by Level of Evidence in Academic versus Nonacademic Serialsi

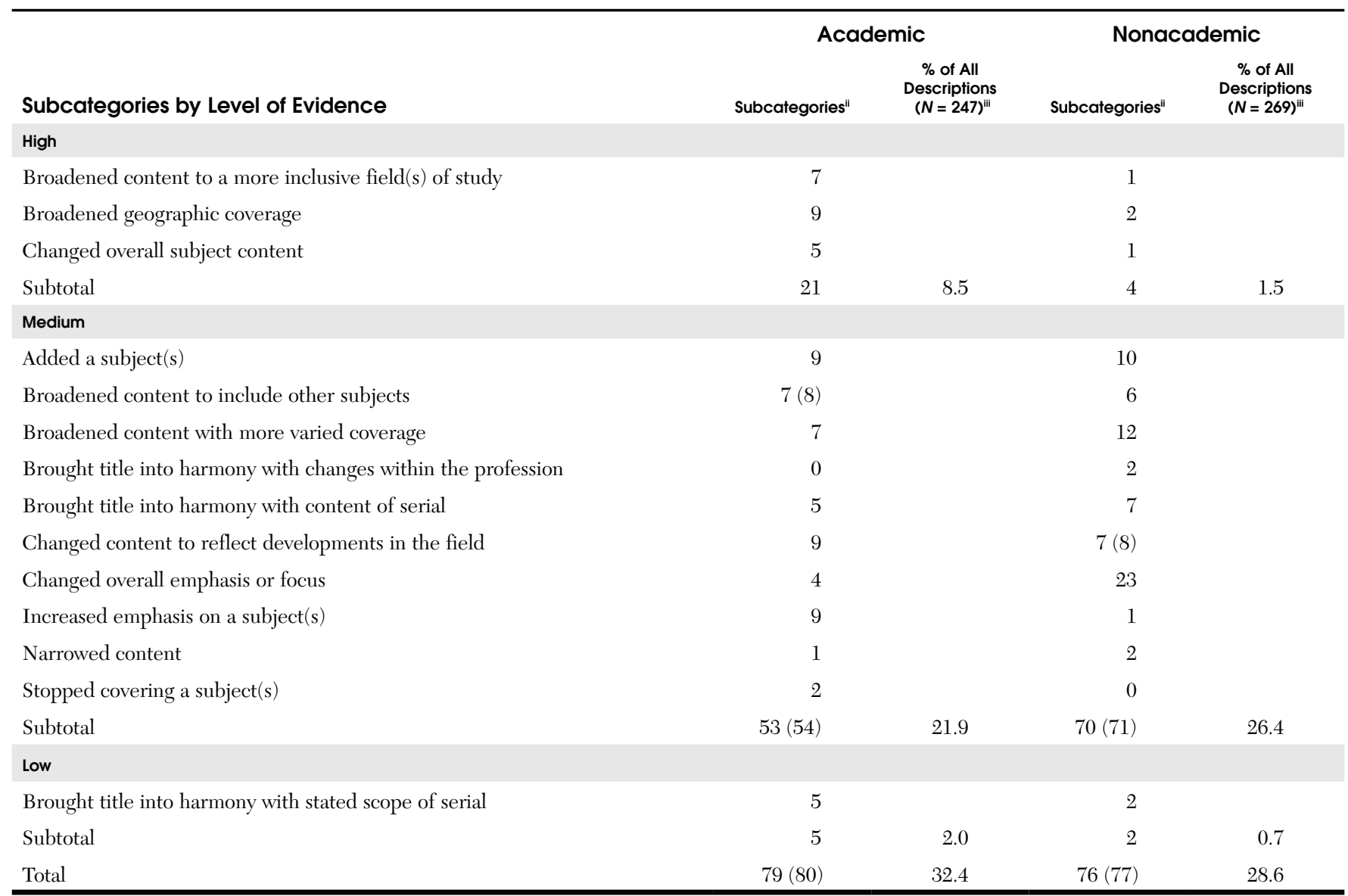

i. This table (columns relating to academic serials) is based on an original paper: Mavis B. Molto, "Identifying Significant Changes in Serials with Title Changes in the Recognition of New Works," Library Resources \& Technical Services 57, no. 4 (October 2013): 198, table 1. Nonacademic serials data were obtained from textual content in the sampled nonacademic serials.

ii. Parenthesized numbers include multiple occurrences of a subcategory for a specific title.

iii. $N=$ Total number of title change descriptions analyzed; percentages are based on parenthesized numbers (when given).

\section{Differences (from title words)}

- Subject changes found overall—academic (57.5 percent), nonacademic (71.5 percent)

- Function changes found overall—academic (51.7 percent), nonacademic (30.0 percent)

- Title word format changes found overall-academic (50.0 percent), nonacademic (60.0 percent)

- Subject change as the primary reason for a title change-academic (56.7 percent), nonacademic (71.5 percent)

- Function change as the primary reason for a title change-academic (28.3 percent), nonacademic (13.8 percent)

\section{Sources of Information in Academic versus Nonacademic Serials}

How do the reasons for title changes from textual content versus title words compare for academic serials versus nonacademic serials? To compare the two subpopulations, the data collected in tables 5 and 6 above were used. Table 5 provides a summary of reasons for title changes found in the combined sources (textual content and title words) whereas table 6 tabulates reasons for title changes that are unique to a single source (only textual content or only title words). The academic and nonacademic serials had both similarities and differences in the reasons found in the two sources, both collectively and uniquely, as summarized below. 
Table 8. Function Change Subcategories by Level of Evidence in Academic versus Nonacademic Serials

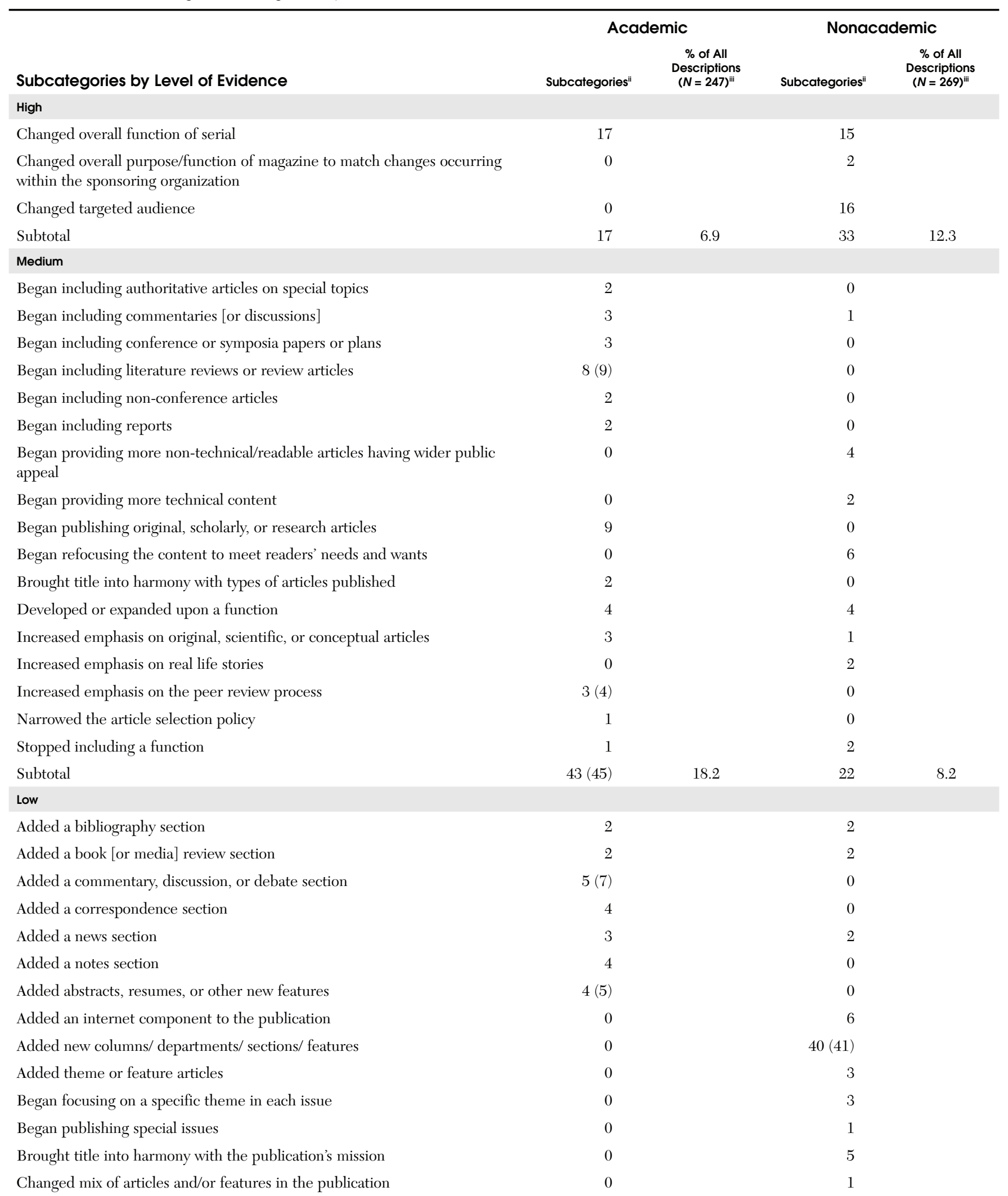


Table 8. Function Change Subcategories by Level of Evidence in Academic versus Nonacademic Serials (continued)i

\begin{tabular}{|c|c|c|c|c|}
\hline Changed or updated a section or feature & $7(10)$ & & 14 & \\
\hline Improved quality and timeliness of content & 0 & & $5(6)$ & \\
\hline Increased or decreased number of articles or length of articles & 0 & & 3 & \\
\hline Subtotal & $31(37)$ & 15.0 & $87(89)$ & 33.1 \\
\hline Total & $91(99)$ & 40.1 & $142(144)$ & 53.6 \\
\hline
\end{tabular}

Table 9. Corporate, Geographic, Frequency, and Title Word Format Change Subcategories in Academic versus Nonacademic Serials'

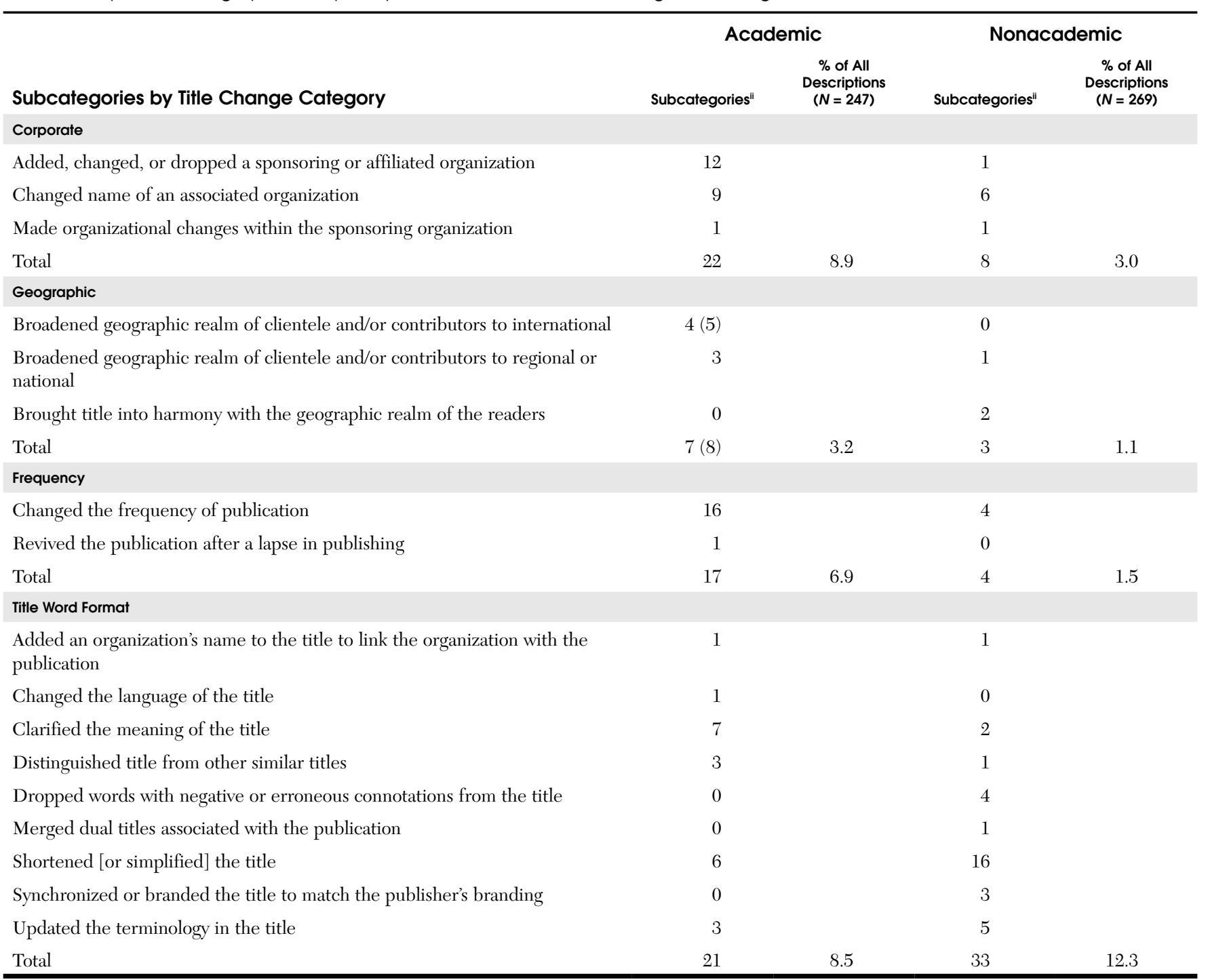

i. Data were obtained from textual content in the sampled serials.

ii. Parenthesized numbers include multiple occurrences of a subcategory for a specific title. 


\section{Similarities}

- Average number of reasons found for a title change (from combined sources)-academic (324/120 = $2.70)$, nonacademic $(335 / 130=2.58)$

- Subject changes found overall (from combined sources)—academic (66.7 percent), nonacademic (76.9 percent)

- Function changes found overall (from combined sources)—academic (67.5 percent), nonacademic (74.6 percent)

- Unique reasons found (from textual content versus title words)—academic (61 text, 137 title), nonacademic (77 text, 138 title)

- Unique title word format changes found (from textual content versus title words)-academic (4 text, 47 title), nonacademic (4 text, 54 title)

\section{Differences}

- Unique subject changes found (from textual content versus title words) — academic (11 text, 20 title), nonacademic ( 7 text, 38 title)

- Unique title word function changes found (from textual content versus title words) —academic (19 text, 17 title), nonacademic (58 text, 5 title)

\section{Subcategories Explaining Title Changes in Academic versus Nonacademic Serials}

How do the subcategories that explain title changes compare for academic serials versus nonacademic serials? To compare the two subpopulations, the subcategory data in tables $7-8$, derived from the textual content of the serials, were used. Subcategories were assigned to the serials to provide a finer classification for explaining the title changes within the six broad categories. The subject subcategories are listed in table 7 and the function subcategories are listed in table 8. The academic and nonacademic serials had both similarities and differences in the identified subcategories, as shown below.

\section{Similarities (from textual content)}

- Subcategory heading counts-academic (48), nonacademic (51)

- Subject subcategory heading counts—academic (13), nonacademic (13)

- Function subcategory heading counts-academic (22), nonacademic (24)

- Subject subcategories-academic (12 same, 1 unique), nonacademic (12 same, 1 unique)

- Corporate subcategories-academic (3 same), nonacademic (3 same)

\section{Differences (from textual content)}

- Function subcategories—academic (9 same, 13 unique), nonacademic (9 same, 15 unique)

- Geographic subcategories—academic (1 same, 1 unique), nonacademic (1 same, 1 unique)

- Frequency subcategories—academic (1 same, 1 unique), nonacademic (1 same)

- Title word format subcategories-academic (5 same, 1 unique), nonacademic (5 same, 3 unique)

\section{Evidence for New Serial Works in Academic versus Nonacademic Serials}

How do the subject and function subcategories that provide evidence for new works compare for academic serials versus nonacademic serials? To compare the two subpopulations, the identified subject and function subcategories were analyzed. A subject or function change was required to identify a new work, according to the model used, whereas a high-level subject or function change provided the concluding evidence for a new work. Data from several tables and appendixes in this and a previous study were used to compare the evidence for new works found in the two subpopulations.

Appendix A in the current study provided information on new works for the nonacademic serials whereas appendix A in a previous study conducted by the author provided information on new works for the academic serials. ${ }^{38}$ The two appendixes contained level-of-evidence codes (high, medium, or low) for the primary subject and function subcategories assigned to the serials. Tables $7-8$ provide level-of-evidence information for all subject and function subcategories (primary and nonprimary). Information on serials for which no subject or function subcategory was assigned was obtained from table 2 .

The academic and nonacademic serials had both similarities and differences with regard to the evidence found for new works. Only the findings from the textual content of the serials were used in the comparisons below.

\section{Similarities (from textual content)}

- New works identified through a primary high-level subject/function change-academic $(35 / 120=29.2$ percent $)$, nonacademic $(32 / 130=24.6$ percent $)$

- Primary medium-level subject/function changesacademic $(56 / 120=46.7$ percent $)$, nonacademic $(58 / 130=44.6$ percent $)$

- Low-level subject changes-academic $(5 / 80=6.3$ percent), nonacademic $(2 / 77=2.6$ percent $)$

- High-level function changes—academic $(17 / 99=17.2$ percent), nonacademic $(33 / 144=22.9$ percent $)$ 


\section{Differences (from textual content)}

- New works identified through a primary high-level subject change—academic $(19 / 120=15.8$ percent $)$, nonacademic $(4 / 130=3.1$ percent $)$

- New works identified through a primary high-level function change-academic $(16 / 120=13.3$ percent $)$, nonacademic $(28 / 130=21.5$ percent $)$

- Primary low-level subject/function changes-academic $(6 / 120=5.0$ percent $)$, nonacademic $(26 / 130=$ 20.0 percent)

- No subject or function change occurred-academic $(23 / 120=19.2$ percent $)$, nonacademic $(14 / 130=$ 10.8 percent)

- High-level subject changes-academic $(21 / 80=26.3$ percent), nonacademic $(4 / 77=5.2$ percent $)$

- Medium-level subject changes-academic $(54 / 80=$ 67.5 percent), nonacademic $(71 / 77=92.2$ percent $)$

- Medium-level function changes-academic $(45 / 99=$ 45.5 percent), nonacademic ( $22 / 144=15.3$ percent)

- Low-level function changes-academic $(37 / 99=37.4$ percent), nonacademic $(89 / 144=61.8$ percent $)$

\section{Highlights of Similarities and Differences between Academic and Nonacademic Serials}

The following are highlights from the foregoing comparisons of similarities and differences between the academic and nonacademic serials. The comparisons are grouped by the source of information used, as follows: title words versus textual content, title words alone, and textual content alone.

\section{Title Words versus Textual Content as the Source}

When comparing findings from title words versus textual content, the academic and nonacademic serials were similar in that many more reasons for title changes were found in the title words than in the textual content. They were also similar in the proportions of unique title-word format changes found in each source but different in the proportions of unique subject changes and unique function changes found. Details follow:

- Similar numbers of reasons found-academic (137 title versus 61 text), nonacademic (138 title versus 77 text)

- Similar numbers of unique title-word format changes-academic (4 text versus 47 title), nonacademic (4 text versus 54 title)

- Different numbers of unique subject changes-academic (20 title versus 11 text), nonacademic (38 title versus 7 text)
- Different proportions of unique function changesacademic (19 text versus17 title), nonacademic (58 text versus 5 title)

\section{Title Words as the Source}

When using title words as the source, it was found that the academic and nonacademic serials were similar in the most frequently found reasons for a title change. The subpopulations were different in the proportions of primary reasons for title changes that were subject changes versus function changes. Details follow:

- Similar frequently found reasons-academic (subject, function, and title word format changes), nonacademic (same)

- Different proportions of subject changes as the primary reason for a title change-academic (56.7 percent), nonacademic (71.5 percent)

- Different proportions of function changes as the primary reason for a title change-academic (28.3 percent), nonacademic (13.8 percent)

\section{Textual Content as the Source}

When using textual content as the source, it was found that the academic and nonacademic serials were similar in the most frequently found reasons for a title change. The subpopulations were also similar with regard to the kinds and proportions of subject changes that occurred. They were different in the kinds and proportions of function changes found. A similar proportion of new works was identified for each subpopulation but through different kinds and proportions of subject versus function changes. The subpopulations also differed in the proportions of serials that had no subject or function change. Details follow:

- Similar frequently found reasons_-academic (subject and function changes), nonacademic (same)

- Similar proportions of subject changes as the primary reason for a title change-academic (50.0 percent), nonacademic (47.7 percent)

- Similar subject subcategories-academic (12 same, 1 unique), nonacademic (12 same, 1 unique).

- Similar proportions of new works identified-academic (29.2 percent), nonacademic (24.6 percent)

- Different proportions of function changes as the primary reason for a title change-academic (30.8 percent), nonacademic (41.5 percent)

- Different function subcategories—academic (9 same, 13 unique), nonacademic (9 same, 15 unique)

- Different proportions of new works identified from subject versus function changes-academic (subject 
15.8 percent, function 13.3 percent), nonacademic (function 21.5 percent, subject 3.1 percent)

- Different proportions of serials with no subject or function change-academic (19.2 percent), nonacademic (10.8 percent)

\section{Limitations of Findings}

Limitations in applying the findings are discussed below in the four areas covered in the study: reasons for title changes, sources of information, subcategories explaining title changes, and evidence for new serial works.

\section{Reasons}

The reasons found for title changes can be generalized to all academic and nonacademic serials with the following limitations: only English-language serials were sampled, thus limiting generalizations to serials in the English language; the samples were not randomly selected, thus requiring that generalizations be tempered until further testing or sampling can be done; and certain kinds of academic and nonacademic serials had prominence in the samples, again suggesting that further sampling may be needed. The sample of academic serials focused on scholarly serials in the social sciences, humanities, and life sciences. The sample of nonacademic serials focused on trade and consumer serials.

\section{Sources}

There are pros and cons to using title words versus textual content in identifying reasons for title changes. Two limitations are noted in this regard: First, title words are often misleading in conveying why a title changed because of the personal interpretations that must be made for the word changes; consequently, generalizing from findings that use title words as the source has limitations. Second, in contrast, textual content (e.g., editorials) generally offers a clear explanation for the title change; however, about half of the sampled serials had no explanation in the text, thus limiting the usefulness of this source. An alternative for serials lacking a textual explanation would be to go directly to the editor or publisher for the information.

\section{Subcategories}

The subcategories devised to explain the title changes can be generalized with the following limitations: First, bias could exist in the way the reasons for title changes were grouped within the subcategories; however, the author anticipated that the proposed subcategories would provide a starting point that could be adjusted through testing and use. Second, the subcategories do not cover all possible explanations for title changes that might occur and will require that additions be made over time.

\section{Evidence}

The proposed approach for recognizing a new work gave prominence to the occurrence of a high-level subject or function change described in the textual content of the serial. The subject and function changes identified in the study were grouped into subcategories that were then ranked according to the evidence provided for a new work. Two limitations relating to the ranking are noted: First, bias could exist in assigning levels to the subcategories. For example, some high-level subcategories might have been classed as medium-level subcategories, and vice versa. The assignment of levels to the subcategories, however, was preliminary, pending input from the serials community. Second, a related issue was how broadly or narrowly to define the concept of a significant change. With a broader interpretation, more new works would be identified, and with a narrower interpretation fewer new works would be identified. This issue will also require discussion by the serials community.

\section{Recommendations}

The purpose of the study was to compare the characteristics of academic and nonacademic serials with title changes and to develop a collective strategy for identifying new works for these serials. Using findings from the study, two proposals were developed for improving the recognition of new works in $R D A$ for serials with title changes. Option $\mathrm{A}$, the ideal approach, correlates with the view of a work as defined in $R D A$, whereas option $\mathrm{B}$, the practical approach, is based on a broader view of the work. The option A rules would require the identification of a significant change in the subject or function of the serial. The option B rules would only require a publisher statement indicating that a totally new serial has emerged. Before discussing the recommendations further, some general observations will be made, along with the identification of factors by which each option will be evaluated.

\section{General Observations}

The following general observations are made from points noted in the literature and from examining the current $R D A$ rules and working with the serials in the two samples.

\section{Sources of Information}

The study's findings show that one cannot determine whether a new work has emerged because of changes in title words because publishers sometimes change titles for 
reasons unrelated to having to do with a change in content or purpose (e.g., to shorten the title or to make the title more appealing). Determining the extent of change in the serial itself from a change in the title is also difficult. Of more value as a source of information are statements by the publisher or editor as to why the title changed.

\section{Concept of a Work}

$R D A$ is based on the FRBR conceptual model in which the concept of a work plays a prominent role. However, the RDA rules for recognizing new works through major changes in the title proper do not (or only coincidentally) identify works that match the RDA definition of a work as a distinct intellectual or artistic creation. The rules do not provide procedures for identifying significant changes in the serial, which is needed to determine whether the serial has changed sufficiently to warrant recognition as a new work. ${ }^{39}$

\section{Boundary of a Work}

No clear way has been found to determine where boundaries between works should be drawn for serials with title changes because serials are in a constant state of change. Attempts can be made to develop criteria for recognizing significant changes and to draw corresponding boundaries, but the boundaries will be artificial because of the difficulty in distinguishing significant from insignificant changes.

\section{Harmonization Requirements}

Descriptions of the international rule-harmonization efforts in the early 2000 s indicate that worthy but somewhat conflicting requirements were set for the rule revision process: the rules should recognize only significant title changes, the rules should recognize deliberate changes in the work, and the rules should be easily understood by a wide variety of people. Significant changes in a title do not always correlate with significant changes in the serial's content or purpose. Also, devising mechanisms that would be easily understood and applied by a variety of people is ideal but does not allow for the analysis needed to confirm that a new work has emerged.

\section{Factors to Consider in Rule Revisions}

The recommendations for RDA rule changes will be evaluated relevant to the following conditions deemed important from points made in the literature as well as when looking at workflow and the requirements of the FRBR model:

1. Number of new works identified: What percentage of serials with title changes would potentially be identified as new works using this approach?
2. Rationale for a new work: What is the rationale underlying the rules relative to identifying new works?

3. Clarity: Would the rules be understandable to catalogers as well as noncatalogers working with serials?

4. Consistency: Could the rules be consistently applied by various catalogers?

5. Efficiency: How much time would be required for a cataloger to apply the rules?

6. Latest or successive entry: If the rules incorporate either latest-entry or successive-entry conventions, how would the issues relevant to these conventions be solved?

7. Harmonization: How would the rules work with the $\operatorname{ISBD}(\mathrm{CR})$ and ISSN international standards? ${ }^{40}$

8. BIBFRAME: How would the rules potentially work in a BIBFRAME environment?

\section{Option A-Ideal Approach}

Option A represents the ideal approach for recognizing new works for serials with title changes. This option requires the identification of either a significant subject change or function change in the serial and draws on findings from the academic and nonacademic serial samples. As the characteristics of the two serial subpopulations were found to be similar in many ways, the recommendations previously made for the academic serials can also be applied to the nonacademic serials, with two addendums, consisting of additional types of function changes that would qualify a serial as a new work. ${ }^{41}$ The recommendations below would require changes to the following RDA rules: rule 6.1.3.2.2, "Major change in the title proper," and 2.3.2.13, "Major and minor changes in the title proper of serials. ${ }^{\text {"42 }}$ The recommendations relate only to title changes in serials and not to other kinds of changes, such as a change in responsibility. The proposed rules are specific to English-language serials but are general enough to have application to non-English-language serials as well, pending additional sampling and testing.

\section{Option A Recommendations}

\section{Source}

Use a credible source to determine the reason for the title change, preferably an explanation within the text of the serial's first issue under the new title.

- If no explanation is found in the serial, assume no significant subject or function change has occurred.

- Optional: If no explanation is found in the serial, contact the editor or publisher directly for an explanation. This may not be possible if the title change occurred in the past and the editor or publisher is no longer available or knowledgeable about the change. 
New Work

Create an access point for a new work when the reason(s) for the title change meets one of the following conditions:

- The subject content of the serial has changed significantly in one of the following ways:

o changed overall subject content

$\circ$ broadened content to a more inclusive field(s) of study

- broadened geographic coverage

- The function of the serial has changed significantly in one of the following ways:

o changed overall function/purpose of serial

o changed overall function/purpose of serial to match changes occurring within the sponsoring organization

$\bigcirc$ changed targeted audience ${ }^{43}$

\section{Analysis of Recommendations}

\section{Number of New Works Identified}

With this option, approximately $12-15$ percent of serials with title changes would be recognized as new works because of findings from the sampling in which about half of the presampled serials had no explanation for the title change and of those having an explanation (250) 25-30 percent had a significant subject or function change.

\section{Rational for a New Work}

This option assumes that serials with title changes become new works because of significant subject or function changes in the serial. The proposed rules are founded on the $R D A$ definition of a work as a distinct intellectual or artistic creation along with the FRBR guidelines for modified works, discussed previously. Further thought is needed, along with input from the serials community, on where the line should be drawn between a significant and insignificant change.

\section{Clarity}

The rules are straightforward but would require interpretation and judgment when determining whether a significant change has occurred. The rules thus might not be easily understood by all people working with serials, especially noncatalogers.

\section{Consistency}

There would likely be some inconsistency in applying the rules because of the judgment required in identifying significant changes.

\section{Efficiency}

Minimal time would be required to apply the rules, which would consist of the following steps: (1) check the serial text for the reason for the title change; (2) if no reason is given, do not create a new record; (3) if a reason is given, apply the criteria for determining whether a significant subject or function change has occurred; and (4) if a significant change has occurred, create a new record or access point. Less time would be required with this approach than with the current RDA rules because fewer new records would be created.

\section{Successive Entry}

This option applies successive-entry principles. A major issue with successive entry is that multiple records must be created, causing issues for catalog users. However, a minimal number of new records would be created with this option, which lessens the problem.

\section{Harmonization}

The new rules would be in conflict with the current ISBD $(\mathrm{CR})$ and ISSN international standards, but the ISSN rules are up for revision in 2017, including plans to consider possible changes to the title-change rules.

\section{BIBFRAME}

It is not known how the rules would work with BIBFRAME, the new framework being tested to replace MARC. BIBFRAME will not consist of records as we currently know them and will instead link information. How successive entry cataloging will work in this new environment is yet to be determined. Whatever problems may occur, however, would likely be similar for both the rules proposed here and the current $R D A$ rules as both are based on successive-entry principles.

\section{Option B-Practical Approach}

Option B represents a more practical approach for recognizing new works for serials with title changes. This option requires a publisher statement indicating the serial has started over as a completely new serial. The recommendations below would require changes to the following $R D A$ rules: rule 6.1.3.2.2, "Major change in the title proper," and rule 2.3.2.13, "Major and minor changes in the title proper of serials. ${ }^{, 44}$ The recommendations relate only to title changes in serials and not to other kinds of changes, such as a change in responsibility. The proposed rules are specific to Englishlanguage serials but are general enough to have application 
to non-English-language serials as well, pending additional sampling and testing.

\section{Option B Recommendations}

\section{Source}

Use a credible source to determine the reason for the title change, preferably an explanation within the text of the serial's first issue under the new title.

- If no explanation is found in the serial, assume no qualifying change has occurred.

- Optional: If no explanation is found in the serial, contact the editor or publisher directly for an explanation.

\section{New Work}

Create an access point for a new work when a publisher statement is found similar to the following: "The serial has started over as a completely new serial."

\section{Analysis of Recommendations}

\section{Number of New Works Identified}

With this option, possibly 1 percent of serials with title changes would be recognized as new works because of findings from the sampling in which about half of the presampled serials had no explanation for the title change and of those having an explanation (250) six potential instances occurred (from the academic sample, twenty Population, thirty-three International Affairs, thirty-four International Affairs Review Supplement; from the nonacademic sample, thirty-seven ColoradoBiz, thirty-eight ColorLines Magazine, eighty-six Nature Canada).

\section{Rationale for a New Work}

This option assumes that serials with title changes remain the same work through successive title changes because of the constant change that occurs in serials and the difficulty in setting boundaries between one work and another. An exception is for the limited circumstance in which the publisher indicates that the serial has started over as a completely different serial. Further investigation is needed, including input from the serials community, to identify the varying language publishers might use to indicate the start of a new serial.

\section{Clarity}

The rules are straightforward but would require interpretation and judgment when determining whether a serial has started over. The rules thus might not be easily understood by all people working with serials, especially noncatalogers.

\section{Consistency}

There would likely be some inconsistency in applying the rules because the judgment required in determining if a serial has started over.

\section{Efficiency}

Minimal time would be required to apply the rules, which would consist of the following steps: (1) check the serial text for the reason for the title change; (2) if no reason is given, do not create a new record; and (3) if a reason is given and indicates a totally new serial has evolved, create a new record or access point. Less time would be required with this approach than with the current $R D A$ rules because the need to create a new record would be rare.

\section{Latest Entry}

This option applies latest-entry principles. A major issue with latest entry is long records because information from all title changes must be entered on a single record. A way of dealing with this might be to collapse the details in records, similar to what is done in complex databases (e.g., the RDA Toolkit, which allows expanding and collapsing of rule details).

\section{Harmonization}

The new rules would conflict with the current $\operatorname{ISBD}(\mathrm{CR})$ and ISSN international standards, but the ISSN rules are due for revision in 2017, including plans to consider possible changes to the title change rules.

\section{BIBFRAME}

It is not known how the rules would work with BIBFRAME, the new framework being tested to replace MARC. BIBFRAME will not consist of records as we currently know them and will instead link information. Thus there will not be an issue with long records, a concern with latest entry cataloging.

\section{Conclusion}

The purpose of the study was to compare the characteristics of academic and nonacademic serials with title changes and to develop a collective strategy for identifying new works for these serials. The characteristics of academic and nonacademic English-language serials were found to be similar in some ways and different in others. Subject and function changes were the most frequently found reasons for title 
changes for both subpopulations, according to explanations found in the sampled serials. There were similarities and differences in the kinds and frequencies of subject and function changes that occurred when a title changed, as indicated by the subcategories used to classify the changes. The subject subcategories were mostly the same for the academic and nonacademic serials whereas the function subcategories were more often different than the same.

Using findings from the study, two proposals were developed for improving the recognition of new works in $R D A$ for serials with title changes: Option $\mathrm{A}$, the ideal approach, follows closely from the findings of the study, requiring a significant subject or function change to occur in the serial. Option B, the practical approach, requires that a publisher statement occur indicating the discontinuance of the previous serial and the start of a completely new serial. Both approaches would result in fewer new records than with the current RDA major/minor rules, with option B resulting in the fewest number of new records.

The two approaches were analyzed according to several criteria to determine how efficiently the rules could be applied and the expected consistency of the results. With both options, minimal time would be required to follow the steps required, including checking the text for the reason(s) for the title change and if a qualifying change occurs creating a new record or access point. Option A would be problematic, however, because of the difficulty in defining a significant change. Option B would be less problematic in that a specific statement would be required indicating the start of a new serial. Inconsistency is likely with both options in how the rules would be applied by various catalogers.

The timing of rule revision is important in light of the efforts that have been made to harmonize rules on an international level. The "Meeting of Experts" in 2000 led to the synchronization of the rules for major and minor title changes in serials between AACR2, ISBD(S), and the ISDS Manual (for ISSN assignment). Since the ISSN rules are currently under review, including consideration of whether the title-change provisions should be updated, the time seems right for also examining the $R D A$ major/minor rules, a carryover from AACR2.

Further research relevant to title changes for serials could be pursued in several areas, including the following:

- Study the characteristics of academic serials with title changes in additional disciplines, such as serials in the physical sciences.

- Study the characteristics of nonacademic serials with title changes for additional subpopulations, such as newspapers, annuals, bulletins, catalogs, and directories, as well as government publications.

- Study the practicality of identifying new works for serials with title changes using the approaches suggested in the current study.

- Seek input from the serials community on where the dividing line should be between a significant and insignificant subject or function change in a serial with a title change.

- Repeat the current study with a sample of nonEnglish-language serials to determine whether additional strategies are needed to identify new works for serials in non-English languages.

\section{References}

1. RDA: Resource Description and Access (Chicago: American Library Association, 2010-), Rule 6.1.3.2.2 and Rule 2.3.2.13, accessed August 17, 2016, http://access.rdatoolkit.org/.

2. RDA, glossary.

3. Mavis B. Molto, "Characteristics of Serial Title Changes and Recognition of New Serial Works: Theoretical and Practical Implications," Serials Review 37, no. 4 (2011): 275-89.

4. Van B. Afes and Paul E. Wrynn, "Biomedical Journal Title Changes: Reasons, Trends, and Impact," Bulletin of the Medical Library Association 81, no. 1 (January 1993): 48-53; Marilyn Geller, "Title Waves," in "Non-Print Serials and Title Waves," by Marilyn Geller and Marlene Sue Heroux, Serials Librarian 17, no. 3-4 (1990): 163-65; S. K. Lakhanpal, "Working with Serials: Title Changes," Indian Librarian 31, no. 1 (1976): 18-32; B. Guha, B. K. Sen, and R. N. Neogi, "On Change of Titles of Periodicals, Part 1," Annals of Library Science and Documentation 22, no. 2 (1975): 45-59; B. Guha, B. K. Sen, and R. N. Neogi, "On the Change of Titles of Periodicals, Part 2," Annals of Library Science and Documentation 22, no. 3 (1975): 93-107; B. Guha, B. K. Sen, and R. N. Neogi, "On Change of Titles of Periodicals, Part 3," Annals of Library Science and Documentation 23, no. 2 (June 1976): 157-68; B. Guha, B. K. Sen, and R. N. Neogi, “On Change of Titles of Periodicals, Pt. 4," Annals of Library Science and Documentation 23, no. 3 (1976): 213-22; B. Guha, B. K. Sen, and R. N. Neogi, "On Change of Titles of Periodicals, Pt. 5," Annals of Library Science and Documentation 24, no. 3-4 (1977): 131-37.

5. Rebecca Soltys Jones, "Serial Title Changes: A Comparison of Scientific, Social Science and Humanities Publications" (master's paper, University of North Carolina at Chapel Hill, 2003); "The Standard Periodical Directory," Oxbridge Communications, 2014, accessed August 17, 2016, http://www.oxbridge .com/SPDCluster/theSPD.asp.

6. Regina Romano Reynolds et al., "The Future of Serials Cataloging, CONSER and the ISSN: Conversations from the Field," Serials Review 41, no. 4 (2015): 231.

7. Stephen Headley, "Comparing and Contrasting Serials in Public and Academic Libraries: How the Other Half Lives," Serials Librarian 48, no. 3-4 (2005): 289-93. 
8. R. S. Jones, "Serial Title Changes," 21.

9. Richard P. Smiraglia, "Further Reflections on the Nature of 'a Work' An Introduction,” Cataloging \& Classification Quarterly 33, no. 3-4 (2002): 1-11.

10. Judith A. Kuhagen, "Modeling Continuing Resources in FRBR [and more]," FRBR Workshop-OCLC, May 2, 2005, slides 12-13, accessed August 17, 2016, http://www .oclc.org/research/events/frbr-workshop/presentations/kuhagen /Kuhagen_OCLC_FRBR.ppt.

11. Kristin Antelman, "Identifying the Serial Work as a Bibliographic Entity," Library Resources \& Technical Services 48, no. 4 (2004): 238-44.

12. Katherine Adams and Britta Santamauro (Kurt Blythe, recorder), "Successive Entry, Latest Entry, or None of the Above? How the MARC21 Format, FRBR and the Concept of a Work Could Revitalize Serials Management," Serials Librarian 54, no. 3-4 (2008): 193-97.

13. IFLA Study Group on the Functional Requirements for Bibliographic Records, Functional Requirements for Bibliographic Records: Final Report, amended and corrected through February 2009 (The Hague: International Federation of Library Associations and Institutions, September 1997), 17, accessed August 17, 2016, http://www.ifla.org/files/cata loguing/frbr/frbr_2008.pdf.

14. Jean L. Hirons, "Reflections on Seriality," Serials Librarian 43, no. 2 (2002): 131.

15. Ed Jones, "What Were They Thinking? Dealing with Serial Title Changes through the Ages" (presentation, CRS Continuing Resources Cataloging Forum, American Library Association Midwinter Meeting, Boston, MA, January 11, 2016), slides 3, 13, 15-16, 21-22, available at CRS Continuing Resources Cataloging Committee website (jones_crcc 2016), accessed August 17, 2016, http://connect.ala.org/node/65933.

16. Ibid., 23, 29-33.

17. Mary Curran, introduction to Mission Accomplished? A Symposium on Latest vs. Successive Entry, edited by Mary Curran, Serials Librarian 53, no. 1-2 (2007): 55-56.

18. Wendy Baia, "Excessive Successive: Time for a Radical Change," Serials Librarian 53, no. 1-2 (2007): 61; Kevin M. Randall, "Latest Entry Legacies: Confessions of a Guerrilla Cataloger," Serials Librarian 53, no. 1-2 (2007): 85-87.

19. Baia, "Excessive Successive," 76-77; Randall, "Latest Entry Legacies," 83, 85, 88.

20. Baia, "Excessive Successive," 71-73; Randall, "Latest Entry Legacies," 87.

21. Jean Hirons, "Seriality: What Have We Accomplished? What's Next?" Cataloging \& Classification Quarterly 36, no. 3-4 (2003): 122, 135-36.

22. Regina Romano Reynolds, "The ISSN Network as an Example of International Cooperative Cataloging," Cataloging d Classification Quarterly 48, no. 2-3 (2010): 178-80.
23. Ibid., 180 .

24. Regina Romano Reynolds, "Revising the ISSN Standard: The Challenge of Change" (presentation, Library of Congress booth, American Library Association Midwinter Meeting, January 2016), slides 23-24, accessed August 17, 2016, http://www.issn.org/wp-content/uploads/2016/02/ISSNRevision _PostALAMW2016.pdf.

25. Mark Sweeney, "Update for 2016 ALA Midwinter Meeting: June-December 2015: ISSN (International Standard Serial Number): Revision of the ISSN Standard (ISO 3297)," Library of Congress, 2015, accessed August 17, 2016, http:// www.loc.gov/ala/mw-2016-update.html.

26. Reynolds et al., "The Future of Serials Cataloging, CONSER and the ISSN," 229.

27. Ibid., 231.

28. Ibid.

29. Ibid.

30. Ibid., 232.

31. Ibid.

32. Kevin Balster, "BIBFRAME for Serials: Activities of the UCLA Continuing Resources Study Group," Serials Review 41, no. 4 (2015): 257-59.

33. Kevin Balster, "Seeing the Forest for the Trees: Serials in a BIBFRAME Environment" (presentation, CRS Continuing Resources Cataloging Forum, American Library Association Annual Conference, Orlando, Florida, June 27, 2016), slides 5-8, available at CRS Continuing Resources Cataloging Committee website, accessed via email July 12, 2016, http://con nect.ala.org/node/65933 (to be posted).

34. RDA, glossary.

35. JSTOR, accessed August 17, 2016, http://www.jstor.org.

36. "Frequently Asked Questions," Ulrichsweb Global Serials Directory, accessed August 17, 2016, http://www.ulrichsweb .com/ulrichsweb/faqs.asp.

37. IFLA Study Group, Functional Requirements for Bibliographic Records, 18

38. Mavis B. Molto, "Identifying Significant Changes in Serials with Title Changes in the Recognition of New Works," Library Resources \& Technical Services 57, no. 4 (2013): 204-7.

39. $R D A$, rule 6.1.3.2 and glossary.

40. The $\operatorname{ISBD}(\mathrm{CR})$ standard for continuing resources replaces the $\operatorname{ISBD}(\mathrm{S})$ standard for serials.

41. Molto, "Identifying Significant Changes," 203.

42. RDA, rule 6.1.3.2.2 and rule 2.3.2.13.

43. The the last two items in this list were added from the nonacademic serial findings.

44. RDA, rule 6.1.3.2.2 and rule 2.3.2.13. 


\section{Appendix A. Sample of Nonacademic Serials with Title Changes'}

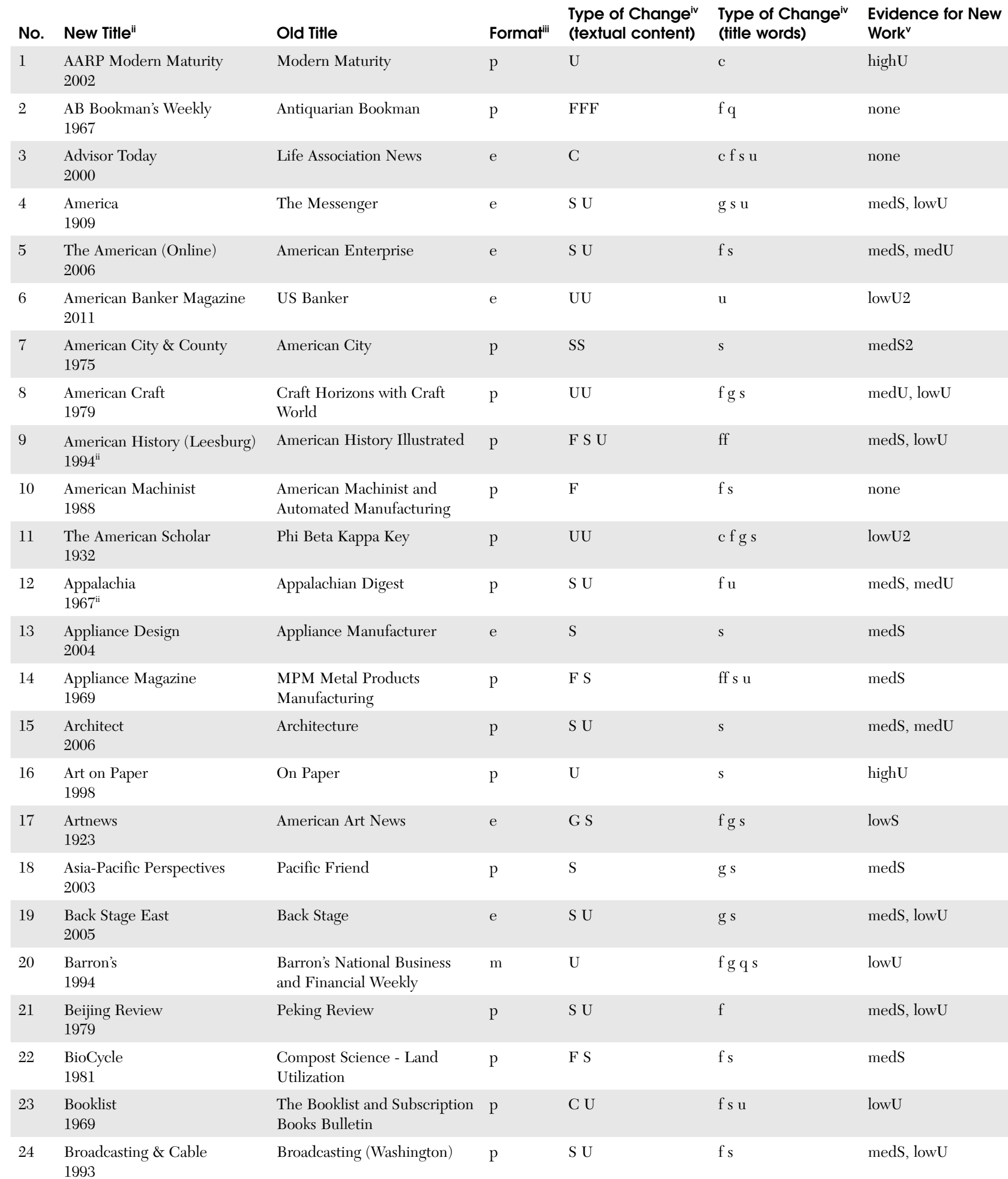




\begin{tabular}{|c|c|c|c|c|c|c|}
\hline No. & New Title & Old Title & Formatiii & $\begin{array}{l}\text { Type of Change } \\
\text { (textual content) }\end{array}$ & $\begin{array}{l}\text { Type of Change } \\
\text { (title words) }\end{array}$ & $\begin{array}{l}\text { Evidence for New } \\
\text { Work }^{\mathrm{v}}\end{array}$ \\
\hline 25 & $\begin{array}{l}\text { Business Horizons } \\
1958\end{array}$ & Indiana Business Review & $\mathrm{p}$ & $\mathrm{S} U \mathrm{UU}$ & $\mathrm{fg} \mathrm{su}$ & highU2,medS \\
\hline 26 & $\begin{array}{l}\text { BusinessWeek } \\
1929^{i i}\end{array}$ & Magazine of Business & $\mathrm{p}$ & UU & fqu & highU, low $\mathrm{U}$ \\
\hline 27 & $\begin{array}{l}\text { California Wild } \\
1997\end{array}$ & Pacific Discovery & $\mathrm{p}$ & SS U & $\mathrm{gs}$ & medS2, lowU \\
\hline 28 & $\begin{array}{l}\text { Campaigns \& Elections } \\
2010\end{array}$ & Politics & $\mathrm{p}$ & $\mathrm{U}$ & s & low $\mathrm{U}$ \\
\hline 29 & $\begin{array}{l}\text { Canada’s History } \\
2010\end{array}$ & The Beaver & e & $\mathrm{U}$ & $\mathrm{g} \mathrm{s}$ & low $\mathrm{U}$ \\
\hline 30 & $\begin{array}{l}\text { Capitol Ideas } \\
2010\end{array}$ & State News & e & S U & $\mathrm{su}$ & medS, low $\mathrm{U}$ \\
\hline 31 & $\begin{array}{l}\text { Carnegie Reporter } \\
2000\end{array}$ & Carnegie Quarterly & $\mathrm{p}$ & Q S & $q u$ & medS \\
\hline 32 & $\begin{array}{l}\text { Chain Store Age } \\
1995\end{array}$ & $\begin{array}{l}\text { Chain Store Age Executive } \\
\text { with Shopping Center Age }\end{array}$ & $\mathrm{p}$ & $\mathrm{U}$ & $\mathrm{fs}$ & $\operatorname{low} \mathrm{U}$ \\
\hline 33 & $\begin{array}{l}\text { Child Education Plus } \\
2007\end{array}$ & Child Education & $\mathrm{p}$ & $\mathrm{U}$ & $\mathrm{u}$ & low $\mathrm{U}$ \\
\hline 34 & $\begin{array}{l}\text { Civil Engineering (Reston) } \\
1983\end{array}$ & Civil Engineering - ASCE & $\mathrm{m}$ & $\mathrm{U}$ & $\mathrm{c}$ ff & $\operatorname{low} \mathrm{U}$ \\
\hline 35 & $\begin{array}{l}\text { Civil War Times } \\
2002\end{array}$ & Civil War Times Illustrated & e & UU & f & $\operatorname{medU}, \operatorname{low} \mathrm{U}$ \\
\hline 36 & $\begin{array}{l}\text { CMA Magazine (English } \\
\text { Edition) } \\
2011\end{array}$ & CMA Management & e & $\mathrm{UU}$ & $\mathrm{fu}$ & highU, low $\mathrm{U}$ \\
\hline 37 & $\begin{array}{l}\text { ColoradoBiz } \\
1999\end{array}$ & Colorado Business Magazine & e & UU & ff $u$ & highU, medU \\
\hline 38 & $\begin{array}{l}\text { ColorLines Magazine } \\
1998\end{array}$ & Third Force & e & S U & $\mathrm{su}$ & highU, medS \\
\hline 39 & $\begin{array}{l}\text { Common Ground } \\
\text { (Washington, DC) } \\
1996\end{array}$ & Federal Archeology & $\mathrm{p}$ & C S U & $\mathrm{fs}$ & medS. lowU \\
\hline 40 & $\begin{array}{l}\text { Community Banker } \\
\text { (Washington, DC 2000) } 2000\end{array}$ & $\begin{array}{l}\text { America’s Community } \\
\text { Bankers }\end{array}$ & $\mathrm{e}$ & $\mathrm{S}$ & $\mathrm{ff} g \mathrm{~s}$ & medS \\
\hline 41 & $\begin{array}{l}\text { The Conference Board } \\
\text { Review } \\
2006\end{array}$ & Across the Board & e & $\mathrm{F} \mathrm{U}$ & $\mathrm{c} \mathrm{u}$ & low $\mathrm{U}$ \\
\hline 42 & $\begin{array}{l}\text { Connected Planet } \\
2009\end{array}$ & Telephony & e & $\mathrm{S} \mathrm{U}$ & s & medS, low $\mathrm{U}$ \\
\hline 43 & $\begin{array}{l}\text { Contract } \\
2000\end{array}$ & Contract Design & e & $\mathrm{F}$ & $\mathrm{fs}$ & none \\
\hline 44 & $\begin{array}{l}\text { Control Solutions } \\
\text { International } \\
2003\end{array}$ & Control Solutions & e & $\mathrm{S}$ & $\mathrm{gs}$ & highS \\
\hline 45 & $\begin{array}{l}\text { Current Health Kids } \\
2010\end{array}$ & Current Health 1 & $\mathrm{e}$ & $\mathrm{U}$ & s & low $\mathrm{U}$ \\
\hline 46 & $\begin{array}{l}\text { Dance Teacher } \\
1999\end{array}$ & Dance Teacher Now & $\mathrm{p}$ & $\mathrm{UU}$ & $\mathrm{f}$ & lowU2 \\
\hline 47 & $\begin{array}{l}\text { Digital Content Producer } \\
2006\end{array}$ & Video Systems & e & $\mathrm{S} \mathrm{U}$ & s & medS, low $U$ \\
\hline
\end{tabular}




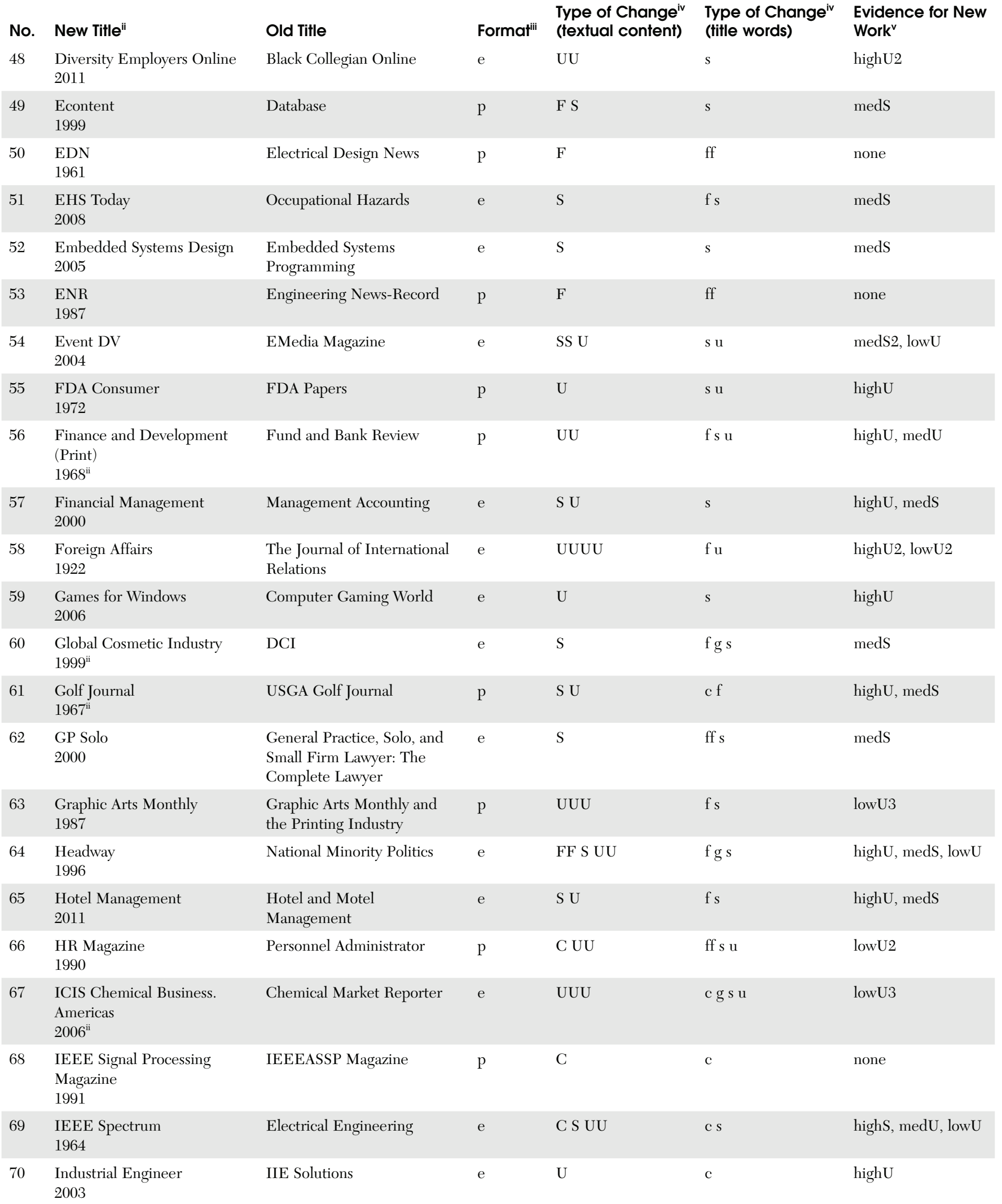




\begin{tabular}{|c|c|c|c|c|c|c|}
\hline No. & New Titleii & Old Title & Formatiii & $\begin{array}{l}\text { Type of Change } \\
\text { (textual content) }\end{array}$ & $\begin{array}{l}\text { Type of Change } \\
\text { (title words) }\end{array}$ & $\begin{array}{l}\text { Evidence for New } \\
\text { Work }^{v}\end{array}$ \\
\hline 71 & $\begin{array}{l}\text { Inside Smithsonian Research } \\
2003\end{array}$ & $\begin{array}{l}\text { Smithsonian Institution. } \\
\text { Research Reports }\end{array}$ & e & UUUU & $\mathrm{fu}$ & lowU4 \\
\hline 72 & $\begin{array}{l}\text { Insight into Diversity } \\
2009\end{array}$ & Affirmative Action Register & e & S U & s u & medS, lowU \\
\hline 73 & $\begin{array}{l}\text { Internet at Schools } \\
2011\end{array}$ & $\begin{array}{l}\text { MultiMedia \& Internet at } \\
\text { Schools }\end{array}$ & e & F S & f s & medS \\
\hline 74 & $\begin{array}{l}\text { JA } \\
1991\end{array}$ & Japan Architect & $\mathrm{p}$ & Q U & ff & lowU \\
\hline 75 & $\begin{array}{l}\text { Kiplinger's Personal Finance } \\
2000\end{array}$ & $\begin{array}{l}\text { Kiplinger's Personal Finance } \\
\text { Magazine }\end{array}$ & $\mathrm{m}$ & UU & $\mathrm{fu}$ & lowU2 \\
\hline 76 & $\begin{array}{l}\text { Library Leadership \& } \\
\text { Management } \\
2009\end{array}$ & $\begin{array}{l}\text { Library Administration and } \\
\text { Management }\end{array}$ & e & C S & s & medS \\
\hline 77 & $\begin{array}{l}\text { Library of Congress Magazine } \\
2012\end{array}$ & $\begin{array}{l}\text { Library of Congress } \\
\text { Information Bulletin }\end{array}$ & $\mathrm{p}$ & $\mathrm{U}$ & $\mathrm{fu}$ & highU \\
\hline 78 & $\begin{array}{l}\text { Long-Term Living } \\
2008\end{array}$ & Nursing Homes & $\mathrm{e}$ & S U & s & medS, lowU \\
\hline 79 & $\begin{array}{l}\text { Material Culture } \\
1984\end{array}$ & Pioneer America & e & SSS UU & g s & $\begin{array}{l}\text { medS3, medU, } \\
\text { lowU }\end{array}$ \\
\hline 80 & $\begin{array}{l}\text { Minnesota History } \\
1925\end{array}$ & Minnesota History Bulletin & e & UUU & $\mathrm{fu}$ & highU, medU, lowU \\
\hline 81 & $\begin{array}{l}\text { Musical Mainstream (Large } \\
\text { Print Edition) } \\
1977\end{array}$ & New Braille Musician & $\mathrm{p}$ & UU & fs & $\operatorname{med} U, \operatorname{low} U$ \\
\hline 82 & $\begin{array}{l}\text { National Parks } \\
1981\end{array}$ & $\begin{array}{l}\text { National Parks and } \\
\text { Conservation Magazine }\end{array}$ & $\mathrm{p}$ & F S U & f s u & highU, lowS \\
\hline 83 & $\begin{array}{l}\text { National Underwriter. Life \& } \\
\text { Health } \\
2004\end{array}$ & $\begin{array}{l}\text { National Underwriter. Life } \\
\text { and Health Financial Services }\end{array}$ & e & $\mathrm{U}$ & $\mathrm{fs}$ & highU \\
\hline 84 & $\begin{array}{l}\text { National Underwriter. P \& C } \\
2004\end{array}$ & $\begin{array}{l}\text { National Underwriter. } \\
\text { Property \& Casualty - Risk } \\
\text { \& Benefits Management } \\
\text { Edition }\end{array}$ & e & UU & $\mathrm{ff} \mathrm{s}$ & lowU2 \\
\hline 85 & $\begin{array}{l}\text { Natural History } \\
1919\end{array}$ & $\begin{array}{l}\text { The American Museum } \\
\text { Journal }\end{array}$ & $\mathrm{p}$ & F S U & $\mathrm{fgsu}$ & medS, medU \\
\hline 86 & $\begin{array}{l}\text { Nature Canada } \\
1972\end{array}$ & Canadian Audubon & $\mathrm{p}$ & C S U & s & highS, highU \\
\hline 87 & $\begin{array}{l}\text { Network World } \\
1986\end{array}$ & On Communications & e & $\mathrm{U}$ & s & low $\mathrm{U}$ \\
\hline 88 & $\begin{array}{l}\text { New Architect } \\
2002\end{array}$ & Web Techniques & $\mathrm{e}$ & F S & s & medS \\
\hline 89 & $\begin{array}{l}\text { New Statesman } \\
1996\end{array}$ & New Statesman \& Society & e & $\mathrm{F}$ & f s & none \\
\hline 90 & $\begin{array}{l}\text { Northern Gardener } \\
2000\end{array}$ & Minnesota Horticulturist & $\mathrm{p}$ & F S & $\mathrm{fgs}$ & medS \\
\hline 91 & $\begin{array}{l}\text { Nuclear Engineering } \\
\text { International } \\
1968\end{array}$ & Nuclear Engineering & $\mathrm{p}$ & G & g s & none \\
\hline 92 & $\begin{array}{l}\text { Office Solutions } \\
2000^{i 1}\end{array}$ & Office Systems (Year) & $\mathrm{p}$ & UU & s & lowU2 \\
\hline 93 & $\begin{array}{l}\text { OfficePro } \\
1997\end{array}$ & The Secretary & e & F U & fs & highU \\
\hline
\end{tabular}




\begin{tabular}{|c|c|c|c|c|c|c|}
\hline No. & New Titleii & Old Title & Formatiii & $\begin{array}{l}\text { Type of Change } \\
\text { (textual content) }\end{array}$ & $\begin{array}{l}\text { Type of Change } \\
\text { (title words) }\end{array}$ & $\begin{array}{l}\text { Evidence for New } \\
\text { Work }^{\mathrm{v}}\end{array}$ \\
\hline 94 & $\begin{array}{l}\text { Outsourced Logistics } \\
2008\end{array}$ & Logistics Today & $\mathrm{e}$ & SSS & $\mathrm{s}$ & highS, medS2 \\
\hline 95 & $\begin{array}{l}\text { PC Magazine (Print) } \\
1986\end{array}$ & $\begin{array}{l}\text { PC: The Independent Guide } \\
\text { to IBM Personal Computers }\end{array}$ & $\mathrm{p}$ & $\mathrm{S} \mathrm{U}$ & $\mathrm{cfsu}$ & medS, lowU \\
\hline 96 & $\begin{array}{l}\text { People \& Strategy } \\
2008\end{array}$ & Human Resource Planning & $\mathrm{p}$ & $S \mathrm{UU}$ & s & highU, medS, lowU \\
\hline 97 & $\begin{array}{l}\text { Preservation } \\
1996\end{array}$ & Historic Preservation & $\mathrm{p}$ & FF U & f s & $\operatorname{low} \mathrm{U}$ \\
\hline 98 & $\begin{array}{l}\text { The Presidency } \\
1998\end{array}$ & Educational Record & e & $\mathrm{S} \mathrm{U}$ & s u & medS, lowU \\
\hline 99 & $\begin{array}{l}\text { Professional Builder } \\
1993\end{array}$ & $\begin{array}{l}\text { Professional Builder and } \\
\text { Remodeler }\end{array}$ & $\mathrm{p}$ & F U & f s & $\operatorname{medU}$ \\
\hline 100 & $\begin{array}{l}\text { Professional Photographer } \\
1999\end{array}$ & $\begin{array}{l}\text { Professional Photographer } \\
\text { Storytellers }\end{array}$ & $\mathrm{p}$ & SSS U & $\mathrm{fs}$ & medS3, lowU \\
\hline 101 & $\begin{array}{l}\text { Prologue (Washington) } \\
1969\end{array}$ & National Archives Accessions & $\mathrm{p}$ & UUUU & $\mathrm{c}$ ff $\mathrm{g} \mathrm{su}$ & $\begin{array}{l}\text { highU2, lowU, } \\
\text { medU }\end{array}$ \\
\hline 102 & $\begin{array}{l}\text { PT in Motion } \\
2009\end{array}$ & $\begin{array}{l}\text { PT - Magazine of Physical } \\
\text { Therapy }\end{array}$ & e & $\mathrm{F} \mathrm{UU}$ & $\mathrm{fu}$ & medU, lowU \\
\hline 103 & $\begin{array}{l}\text { Quality Progress } \\
1968\end{array}$ & Industrial Quality Control & $\mathrm{p}$ & S UU & $\mathrm{fs}$ & medS, lowU2 \\
\hline 104 & $\begin{array}{l}\text { Raising Black [and Biracial] } \\
\text { Children } \\
1999^{\mathrm{ii}}\end{array}$ & Black Child: the African & e & $\mathrm{U}$ & s & $\operatorname{medU}$ \\
\hline 105 & $\begin{array}{l}\text { Rosie } \\
2001\end{array}$ & McCall's & $\mathrm{m}$ & S UU & c & medS, medU, low $\mathrm{U}$ \\
\hline 106 & $\begin{array}{l}\text { Russian Life } \\
1993\end{array}$ & Soviet Life & $\mathrm{p}$ & SSS & $\mathrm{fgs}$ & medS3 \\
\hline 107 & $\begin{array}{l}\text { Sales and Marketing } \\
\text { Management } \\
1975\end{array}$ & Sales Management & $\mathrm{m}$ & $\mathrm{F}$ & s & none \\
\hline 108 & $\begin{array}{l}\text { Salt Lake } \\
1998^{\text {ii }}\end{array}$ & Salt Lake City & $\mathrm{p}$ & $\mathrm{F}$ & f & none \\
\hline 109 & $\begin{array}{l}\text { Saturday Evening Post } \\
1839\end{array}$ & $\begin{array}{l}\text { Atkinson's Evening Post and } \\
\text { Philadelphia Saturday News }\end{array}$ & e & S U & $\mathrm{fgsu}$ & medS, lowU \\
\hline 110 & $\begin{array}{l}\text { Scandinavian Review } \\
1975\end{array}$ & $\begin{array}{l}\text { The American-Scandinavian } \\
\text { Review }\end{array}$ & $\mathrm{p}$ & $\mathrm{U}$ & $\mathrm{fgs}$ & highU \\
\hline 111 & $\begin{array}{l}\text { School Library Monthly } \\
2009\end{array}$ & $\begin{array}{l}\text { School Library Media } \\
\text { Activities Monthly }\end{array}$ & $\mathrm{e}$ & F UUU & $\mathrm{fs}$ & medU, lowU2 \\
\hline 112 & $\begin{array}{l}\text { Science News } \\
1966\end{array}$ & Science News Letter & $\mathrm{e}$ & $\mathrm{F}$ & $\mathrm{fu}$ & none \\
\hline 113 & $\begin{array}{l}\text { Sierra } \\
1977\end{array}$ & Sierra Club Bulletin & $\mathrm{p}$ & UU & $\mathrm{cfu}$ & highU, lowU \\
\hline 114 & $\begin{array}{l}\text { Skeptical Inquirer } \\
1978\end{array}$ & The Zetetic & $\mathrm{p}$ & Q U & $\mathrm{fs}$ & $\operatorname{low} \mathrm{U}$ \\
\hline 115 & $\begin{array}{l}\text { Sound \& Vision } \\
2001^{\mathrm{ii}}\end{array}$ & $\begin{array}{l}\text { Stereo Review's Sound and } \\
\text { Vision }\end{array}$ & $\mathrm{p}$ & $\mathrm{S}$ & $\mathrm{fsu}$ & medS \\
\hline
\end{tabular}




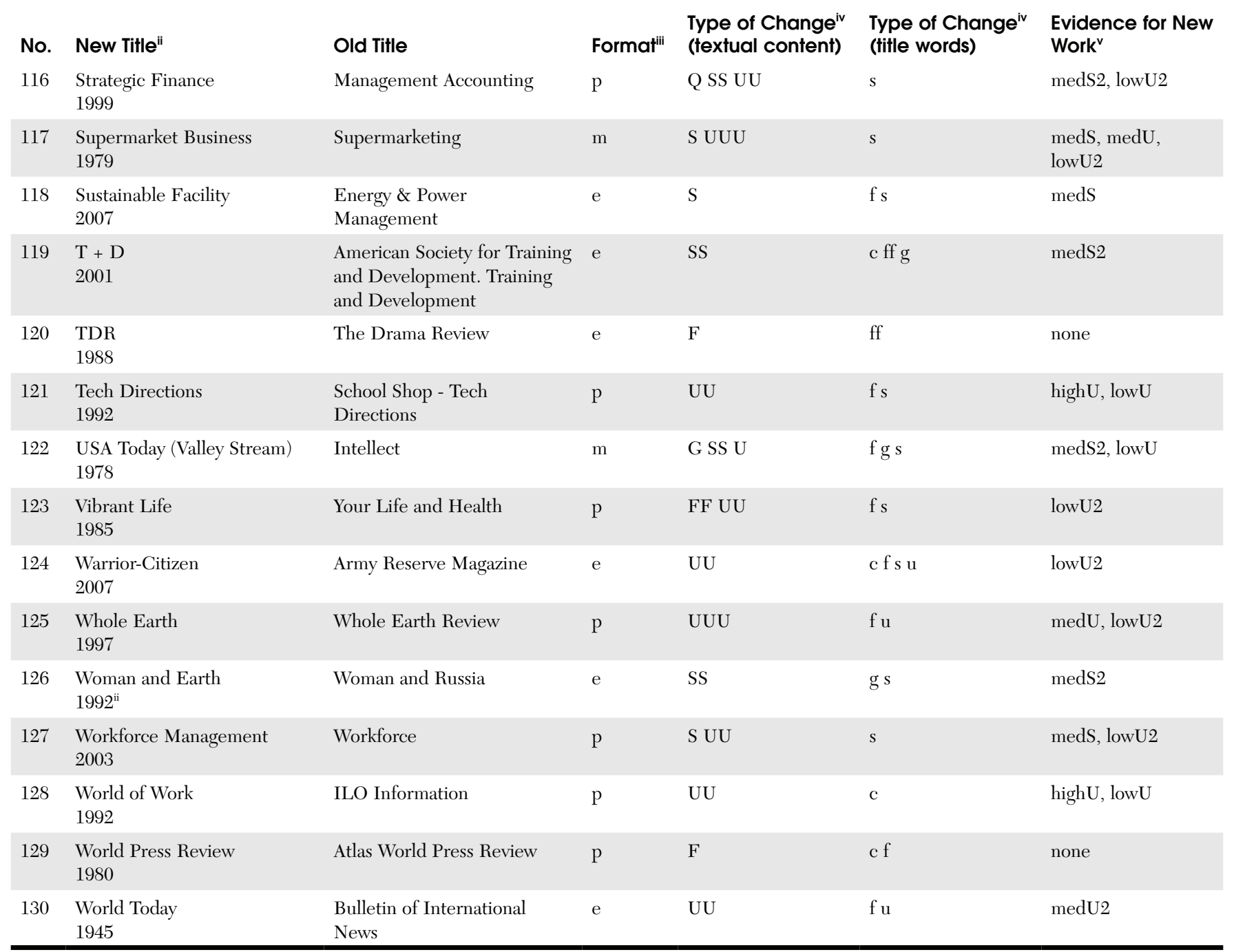

i. Sample derived from serials listed in Ulrichsweb.

ii. Year began: obtained/clarified when needed from OCLC records.

iii. Format of serial sampled: $\mathrm{e}=$ electronic, $\mathrm{m}=$ microfilm, $\mathrm{p}=$ print .

iv. Type of change: $\mathrm{C} / \mathrm{c}=$ Corporate change; $\mathrm{F} / \mathrm{f}=$ Title word format change; $\mathrm{G} / \mathrm{g}=$ Geographic change; $\mathrm{Q} / \mathrm{q}=$ Frequency change; $\mathrm{S} / \mathrm{s}=\mathrm{Subject}$ change; $\mathrm{U} / \mathrm{u}=$ Function change.

v. Evidence for new work: highS/U = high level of evidence from a Subject/Function change (32); medS/U = medium level of evidence from a Subject/ Function change (58); lowS/U = low level of evidence from a Subject/Function change (26); none = no evidence (14). Numbers following codes indicate more than one occurrence of the subject or function change (e.g., "medU2" indicates two occurrences of a medium level function change). 


\section{Appendix B. Title Change Categories}

\author{
Category \\ Textual Content Guidelines \\ Corporate \\ Change \\ Changes in [or within] the serial's corporate, society, or other \\ affiliations, including name changes \\ Example: changed Club name \\ 1. Bulletin of the Torrey Botanical Club \\ 2. Journal of the Torrey Botanical Society
}

Title Word Changes in the serial's title words for the purpose of: clarifying Format title, distinguishing title from another title, updating terminology, Change changing language, shortening title, [making title appealing to a broader or different audience, emphasizing corporate sponsorship, or developing consistency with a publisher's/sponsor's other publications]

Example: updated terminology

1. Black American Literature Forum

2. African American review

Geographic Changes in the [geographic realm of the] serial's clientele, memChange

bership, or contributors

1. Midwest journal of political science

2. American journal of political science
Example: changed to national

\section{Title Word Guidelinesii}

Changes, additions, or deletions of corporate, society, or other organizational names in the title

Example: deleted Federation name

1. Research journal of the Water Pollution Control Federation

2. Water environment research

Changes in the format of the title or title words, including: replacing acronym with spelled-out form or other words, replacing spelled-out form with acronym, adding words to acronym, adding/changing qualifying words, updating/[simplifying] terminology, changing language, shortening title

Example: shortened title

1. Journal of the Royal African Society

2. African affairs

Changes, additions, or deletions of title words denoting the geographic realm of the serial, including words in corporate names [No attempt was made to discern if a geographic word occurred with reference to the serial's domain of readers/contributors or to the serial's subject content. Geographic words were counted in both categories as seemed applicable.]

Example: changed to regional

1. California folklore quarterly

2. Western folklore

Changes, additions, or deletions of title words describing the frequency of the serial

Example: changed to quarterly

1. The semi-annual (Agassiz Association. Department of the Wilson Chapter)

2. The Wilson quarterly

$\begin{array}{ll}\text { Subject } & \text { Changes in the serial's subject content } \\ \text { Change } & \text { Example: changed to literature } \\ & \text { 1. Nineteenth-century fiction } \\ & \text { 2. Nineteenth-century literature }\end{array}$

Changes, additions, or deletions of title words denoting subjects [or topical content], including words in corporate names [and geographic names]. [Acronyms (corporate and non-corporate) were included in the subject analysis.]

Example: changed to biology

1. Systematic zoology

2. Systematic biology

Function Changes in the serial's character or purpose [or targeted audi-

Change ence]

Example: changed to journal

1. Bulletin of the American Musicological Society

2. Journal of the American Musicological Society

Changes, additions, or deletions of title words describing the function of the serial

Example: changed to review

1. The south central bulletin

2. South central review

\footnotetext{
i. This table is based on an original paper published in Taylor \& Francis: Mavis B. Molto, "Characteristics of Serial Title Changes and Recognition of New Serial Works: Theoretical and Practical Implications," Serials Review 37, no. 4 (2011): 279, table 2. Bracketed information represents modifications added to the guidelines when performing the current study.

ii. Examples show old title (number 1), followed by new title (number 2).
} 